\title{
Biological therapy in Psoriasis: An emphasis on its dermatologic adverse events
}

\author{
Pasita Palakornkitti, ${ }^{1}$ Kulsupa Nimmannitya, ${ }^{1}$ Ploysyne Rattanakaemakorn ${ }^{1}$
}

\begin{abstract}
Objective: To report an overview of dermatologic adverse events (AEs) related to biologics used for psoriasis and compare common dermatologic AEs across different biologic classes.
\end{abstract}

Data Sources: A comprehensive search in MEDLINE via PubMed from inception through June 9, 2021, was conducted.

Study Selections: The selection process was performed independently by two reviewers. Studies were eligible if patients were diagnosed with plaque-type psoriasis, were treated with biologics, and had $\geq 1$ dermatologic AE.

Results: A total of 1023 records were identified, and 127 studies were included. The incidence of dermatologic AEs was $4.17 \%$ for tumor necrosis factor- $\alpha$ (TNF- $\alpha$ ) inhibitors, $9.49 \%$ for interleukin (IL)-12/23 inhibitor, $12.40 \%$ for IL-17 inhibitors, and $7.37 \%$ for IL-23 inhibitors. Biologic-related dermatological AEs can be classified into allergic skin reactions, inflammatory skin diseases, skin infections, skin neoplasms, and miscellaneous AEs. An evident class effect was observed. Skin neoplasms (1.45\%), mainly nonmelanoma skin cancer (1.36\%), predominated among TNF- $\alpha$ inhibitors. Allergic skin reactions (6.25\%) were frequently reported with IL-12/23 inhibitor. During treatment with IL-17 inhibitors, skin infections (5.01\%) were common, and the most common was driven by mucocutaneous candidiasis (4.85\%). Inflammatory skin disease $(2.32 \%)$, mainly eczematous eruptions $(0.84 \%)$, dominated in IL-23 inhibitors.

Conclusions: A predominance of specific dermatologic AEs appears in distinct biologic classes due to their different specific targets of action. Further study is needed to understand the mechanisms of these potential AEs, which will help in their management.

Key words: Infliximab, adalimumab, etanercept, ustekinumab, secukinumab, ixekizumab, brodalumab, bimekizumab, guselkumab, tildrakizumab, risankizumab, skin (cutaneous), safety, side effect, AE, ADR

\begin{abstract}
Affiliations:
${ }^{1}$ Division of Dermatology, Department of Medicine, Faculty of Medicine Ramathibodi Hospital, Mahidol University, Bangkok, Thailand
\end{abstract}

\section{Introduction}

Psoriasis is a chronic systemic immune-mediated skin disease affecting $0.09 \%$ to $5.1 \%$ of the general population. ${ }^{1}$ Knowledge about the immunopathogenesis of psoriasis has transformed the therapeutic approach toward targeted therapy. Biologics, representing targeted therapy, refer to complex molecules including monoclonal antibodies and receptor fusion proteins that target specific parts of the immune responses. The targets of currently available biologics for the treatment of psoriasis are tumor necrosis factor- $\alpha$ (TNF- $\alpha$ ), the interleukin 12 (IL-12)/T-helper 1 (Th1) pathway,

\section{Corresponding author:}

Ploysyne Rattanakaemakorn

Division of Dermatology, Department of Medicine,

Faculty of Medicine Ramathibodi Hospital, Mahidol University,

270 Rama VI Road, Ratchathewi, Bangkok 10400, Thailand

E-mail: Ploysyne@gmail.com

and the IL-23/Th17 pathway, which play crucial roles in psoriasis pathogenesis. ${ }^{2-4}$

Currently, US Food and Drug Administration (FDA)-approved biologics for psoriasis (excluding biosimilars) are infliximab, adalimumab, etanercept, certolizumab, ustekinumab, secukinumab, ixekizumab, brodalumab, guselkumab, tildrakizumab, and risankizumab., Most of these drugs showed excellent efficacy with an acceptable safety profile. However, the expanding use of biologics is inevitably accompanied by the emergence of new adverse events (AEs). Dermatologic AEs 
have frequently been reported in studies and clinical experiences, posing a significant challenge for physicians. Due to their different targets of action, various dermatologic AEs have been observed across each biologic class. ${ }^{3,4}$ This review aims to report an overview of dermatologic AEs related to biologics used for psoriasis and compare common dermatologic AEs across different biologic classes.

\section{Methods}

\section{Literature search}

A comprehensive search in MEDLINE via PubMed from inception through June 9, 2021, was conducted. The search terms included the following: "psoriasis," or "psoriatic," combined with either "skin," or "cutaneous," combined with either "safety," or "adverse," and one of the following: "infliximab," "adalimumab," "etanercept", “certolizumab," "ustekinumab," "secukinumab," “ixekizumab," "brodalumab," "bimekizumab," "guselkumab," "tildrakizumab," or "risankizumab".

The search terms aimed to include all dermatologic AEs related to FDA-approved biologics for patients with psoriasis. To be comprehensive, bimekizumab, an FDA approval-pending biologic for moderate-to-severe plaque psoriasis (as of July 2021), was also included in the present review.

\section{Study selections}

Study selections were performed independently by two reviewers. All references were screened to identify eligible studies. The language was limited to English. Studies were eligible if patients were diagnosed with plaque-type psoriasis, were treated with infliximab, adalimumab, etanercept, certolizumab, ustekinumab, secukinumab, ixekizumab, brodalumab, bimekizumab, guselkumab, tildrakizumab, or risankizumab, and had $\geq 1$ dermatologic AE. Patients diagnosed with other types of psoriasis without plaque-type psoriasis, treated with more than one biologic agent, treated with concurrent therapy, or treated with biosimilars were excluded. Pool analysis and subgroup analysis were also excluded. A flow diagram of the study selection process is shown in Figure 1.

\section{Data analysis}

Reported dermatologic AEs from all types of studies, including case series and case reports, were included to reflect all dermatologic AEs following the use of biologics, and are presented as the number of reported cases $(\mathrm{N})$. In contrast, comparisons across biologic classes were performed using the rate of dermatologic AEs (\%) calculated based on data from clinical and observational studies.

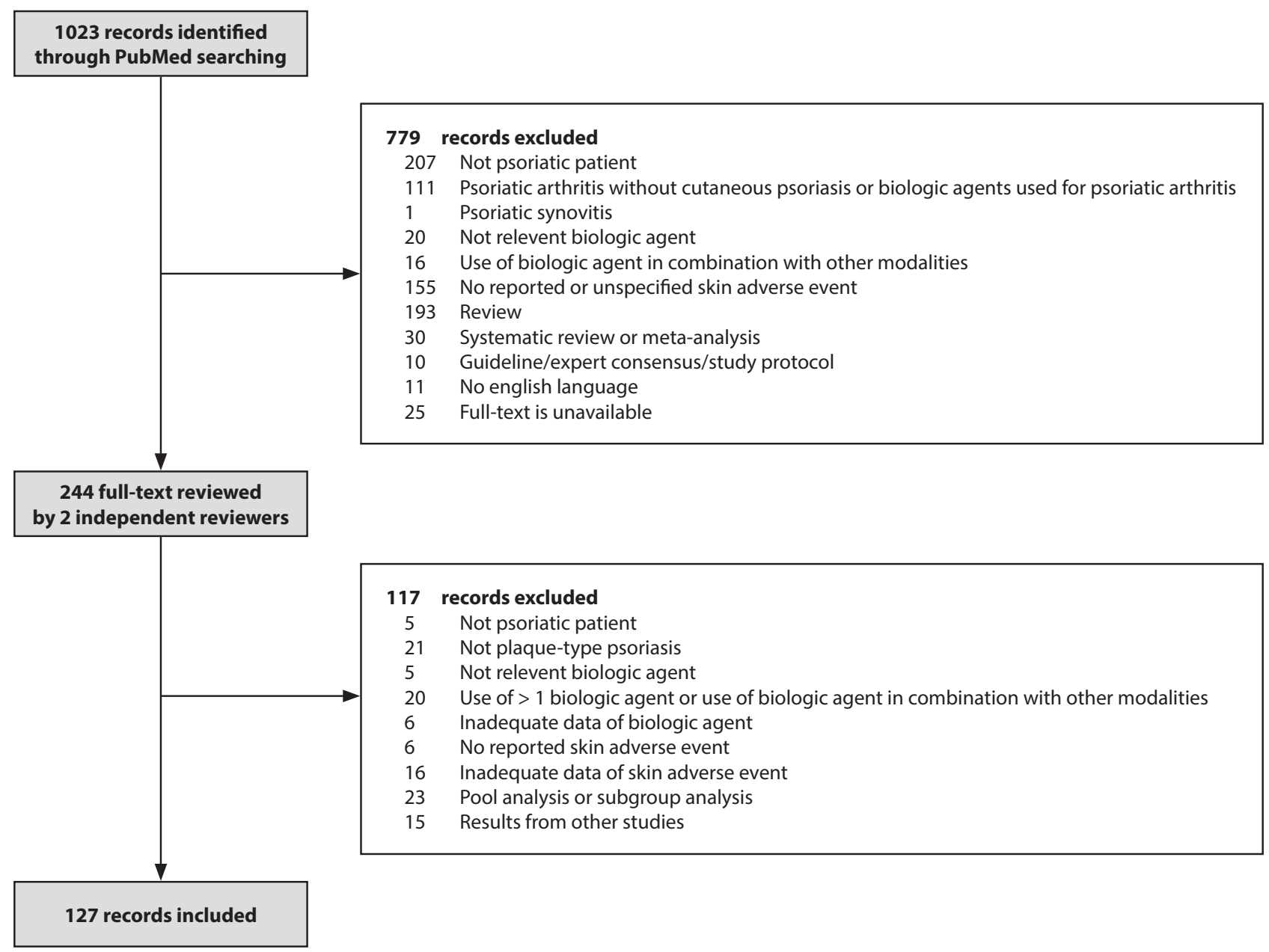

Figure 1. A flow diagram of study selection process. 


\section{Results}

A total of 1023 records were identified from PubMed. After the papers were screened and reviewed, 127 eligible studies (41 clinical studies, 14 observational studies, 16 case series, and 56 case reports) were included. Of these studies, 76 were related to TNF- $\alpha$ inhibitors ( 25 infliximab, 25 adalimumab, 26 etanercept, and 0 certolizumab), 16 were related to IL-12/23 inhibitor (16 ustekinumab), 36 were related to IL17 inhibitors (19 secukinumab, 8 ixekizumab, 5 brodalumab, and 4 bimekizumab), and 11 were related to IL-23 inhibitors (5 guselkumab, 3 tildrakizumab, 3 risankizumab). Regarding clinical and observational studies, the total number of studied patients was 671 for infliximab, 11,226 for adalimumab, 3,340 for etanercept, 4,614 for ustekinumab, 3,153 for secukinumab, 3,370 for ixekizumab, 2,620 for brodalumab, 1,011 for bimekizumab, 1,171 for guselkumab, 532 for tildrakizumab, and 930 for risankizumab. The details of all eligible studies are provided in Supplementary Table 1.

\section{Review}

The initiation of pathogenesis in psoriasis is triggered by predisposing genotype and external factors. These triggers disrupt keratinocytes, which then release self-deoxyribonucleic acid (DNA) and the antimicrobial peptide LL37 (cathelicidin). Self-DNA and pathogen-derived DNA bind with LL37 and form a complex that activates plasmacytoid dendritic cells (DCs). Plasmacytoid DCs release type 1 interferons (IFNs) and TNF- $\alpha$, which promote myeloid DCs. Subsequently, the T-cell mediated immune response becomes greatly exaggerated resulting in the release of cytokines related to keratinocyte activation and proliferation, plus the recruitment and activation of further inflammatory cells. Currently available biologics aim to target specific parts of the immunopathogenesis of psoriasis. The target sites of biologics in psoriasis are illustrated in Figure 2.,4

Dermatologic AEs observed during biologic treatment could be categorized into five groups: allergic skin reactions, inflammatory skin diseases, skin infections, skin neoplasms, and miscellaneous AEs. The highest incidence of dermatologic AEs was reported during IL-17 inhibitor treatment (12.40\%), followed by IL-12/23 inhibitor (9.49\%), IL-23 inhibitor $(7.37 \%)$, and TNF- $\alpha$ inhibitor $(4.17 \%)$ treatment. The dominances of dermatologic AEs across biologic classes varied, suggesting a class effect. Skin neoplasms, allergic skin reactions, skin infections, and inflammatory skin diseases predominated in TNF- $\alpha$ inhibitors, IL-12/23 inhibitor, IL-17 inhibitors, and IL-23 inhibitors, respectively (Figure 3 ). The three most common dermatologic AEs are ranked and illustrated by biologic class in Figure 4 .

\section{TNF- $\alpha$ inhibitors}

TNF- $\alpha$ is a proinflammatory cytokine involved in various steps in the immunopathogenesis of psoriasis. $^{2}$

Previous studies demonstrated an increased risk of nonmelanoma skin cancer (NMSC) in patients administered TNF- $\alpha$ inhibitors, while the risk of melanoma remained inconclusive. ${ }^{6-8}$ The relative risk of NMSC is 2.02 in patients receiving TNF- $\alpha$ inhibitor treatment, the majority of which are basal cell carcinoma and squamous cell carcinoma. ${ }^{9}$ Consistent with previous findings, our review observed a predominance of skin neoplasms in TNF- $\alpha$ inhibitors (1.45\%), especially NMSCs (1.36\%). Regarding the 231 reported NMSCs, 138 were observed in patients treated with adalimumab (Table 1). Similarly, the number of melanomas observed in patients treated with TNF- $\alpha$ inhibitors was higher than those treated with IL-12/23 inhibitor, IL-17 inhibitors, and IL-23 inhibitors. Since TNF- $\alpha$ regulates many facets of cell function, including proliferation, activation, differentiation, and apoptosis, blocking TNF- $\alpha$ may disturb the tumor suppression mechanism through the inhibition of TNF- $\alpha$ cytotoxic effects. Consequently, TNF- $\alpha$ inhibitors may induce rapid proliferation of epithelial tumors. ${ }^{2,10}$ However, there are some limitations due to data on the risk of cancer from the included studies. Assuming that most of the patients with moderate-to-severe psoriasis encountered several immunosuppressive treatments before receiving TNF- $\alpha$ inhibitors, some were treated with psoralen and UVA (PUVA), which are associated with an increased NMSC risk, ${ }^{11}$ it is difficult to conclude that NMSC is specifically attributable to biologic therapy alone.

Allergic skin reactions (1.24\%) were also frequently reported in patients treated with TNF- $\alpha$ inhibitors which mainly contributed to injection site reactions (ISRs) $(0.72 \%)$ and infusion reactions $(0.43 \%)$ (Table 1$)$. Factors associated with injection site pain and ISRs include $\mathrm{pH}$, volume and excipients, temperature, and the injection process, while patient-related factors, such as low body weight, and female sex, can make an individual more susceptible. ${ }^{12}$ Thoumaidou et al., ${ }^{13}$ reported high incidences of ISRs (> 5\%) during etanercept and adalimumab treatment, which were higher than our findings. This could be explained by different patient conditions and numbers of patients. The incidence of infusion reactions following infliximab was $9.69 \%$. The immediate infusion reactions to infliximab result from rapid infusion rate-related $\mathrm{cy}$ tokine release from the local immune cells. A recent systematic review discussed primary prevention by a gradual increase in the infusion rate, co-administration of immunomodulators, and premedication with corticosteroids, antihistamines, and antipyretics, plus proposed a management algorithm for infusion reactions. ${ }^{14}$

Bacterial and viral infections were frequently observed during TNF- $\alpha$ inhibitor treatment. The rates of bacterial, viral, and fungal infections were $0.35 \%, 0.20 \%$, and $0.09 \%$, respectively. The blockade of TNF- $\alpha$-mediated immune responses can interfere with innate and cell-mediated immune responses by suppressing IFN- $\gamma$ effects, reducing $\mathrm{T}$ cell activity, and interfering with granuloma formation and stabilization. ${ }^{15-17}$ TNF- $\alpha$ inhibitors are likely to increase the risk of all granulomatous infections, including tuberculosis and nontuberculous mycobacterial infections (NTMs). However, with the exception of tuberculosis, relatively little data has been published on this association. ${ }^{18}$ In this review, cutaneous NTM was found in 2 patients (1 Mycobacterium haemophilum infection and 1 Mycobacterium poriferae) following infliximab and etanercept treatment. 


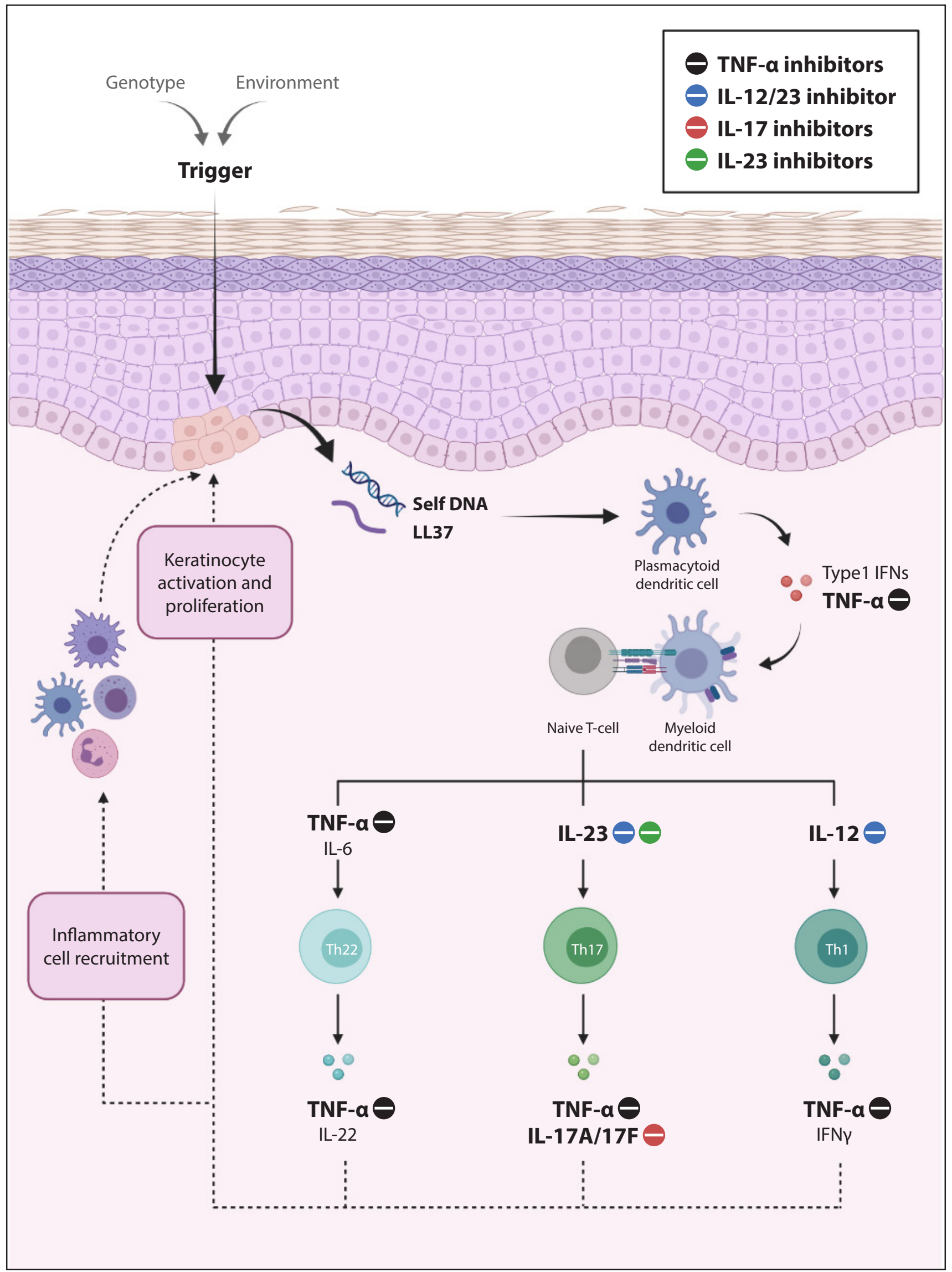

Figure 2. Target of biologics in the immunopathogenesis of psoriasis.

TNF- $\alpha$ inhibitors, IL-12/23 inhibitor, IL-17 inhibitors, and IL-23 inhibitors target specific parts of the immunopathogenesis of psoriasis.

DNA deoxyribonucleic acid; IFNs, interferons; IL, interleukin; TNF, tumor necrosis factor 


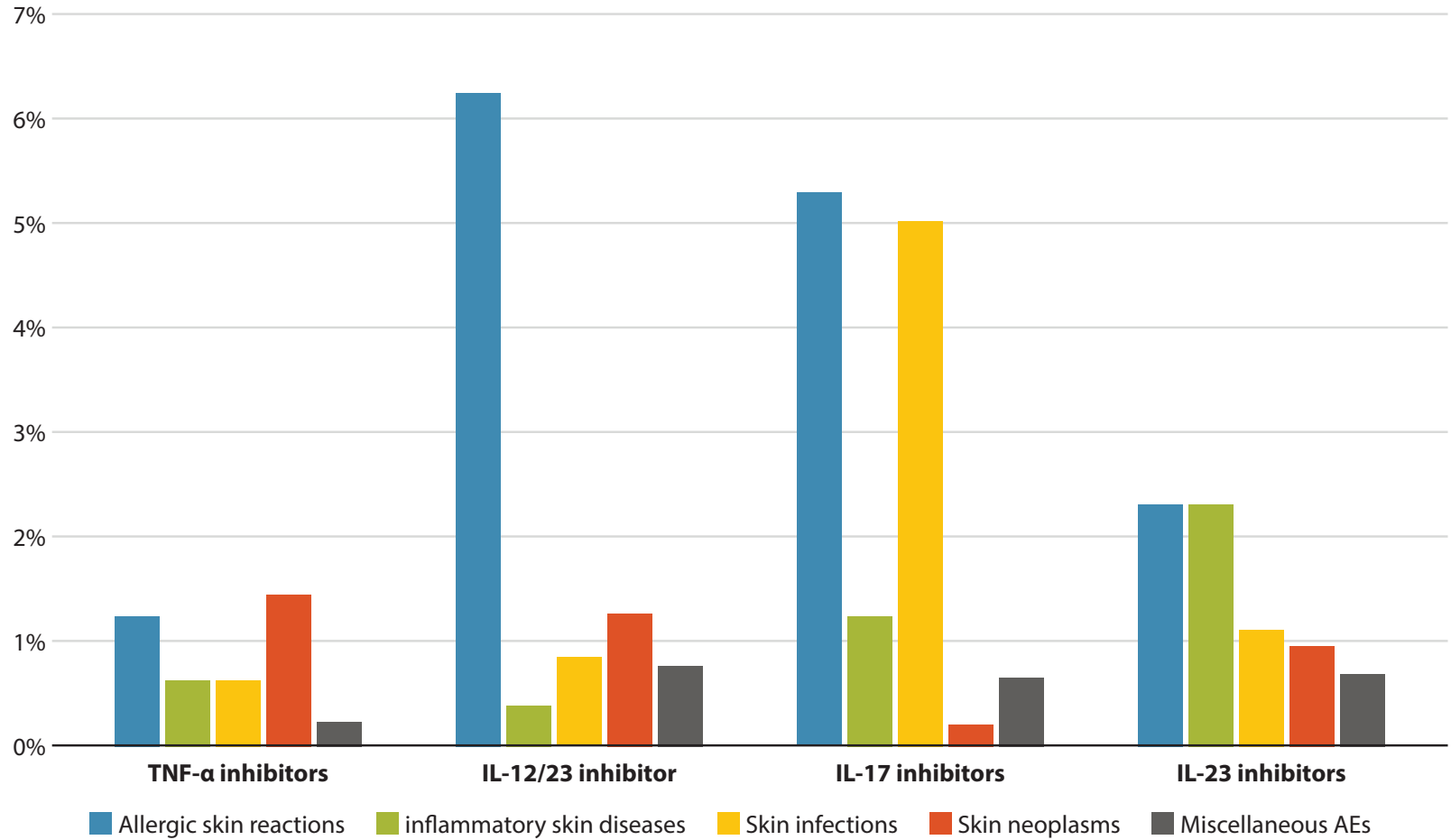

Figure 3. Overview of dermatologic adverse events by biologic class.

Bar graphs represent the rate of dermatologic adverse events (\%) by biologic class based on data from clinical and observational studies.

AE, adverse event; IL, interleukin; TNF, tumor necrosis factor

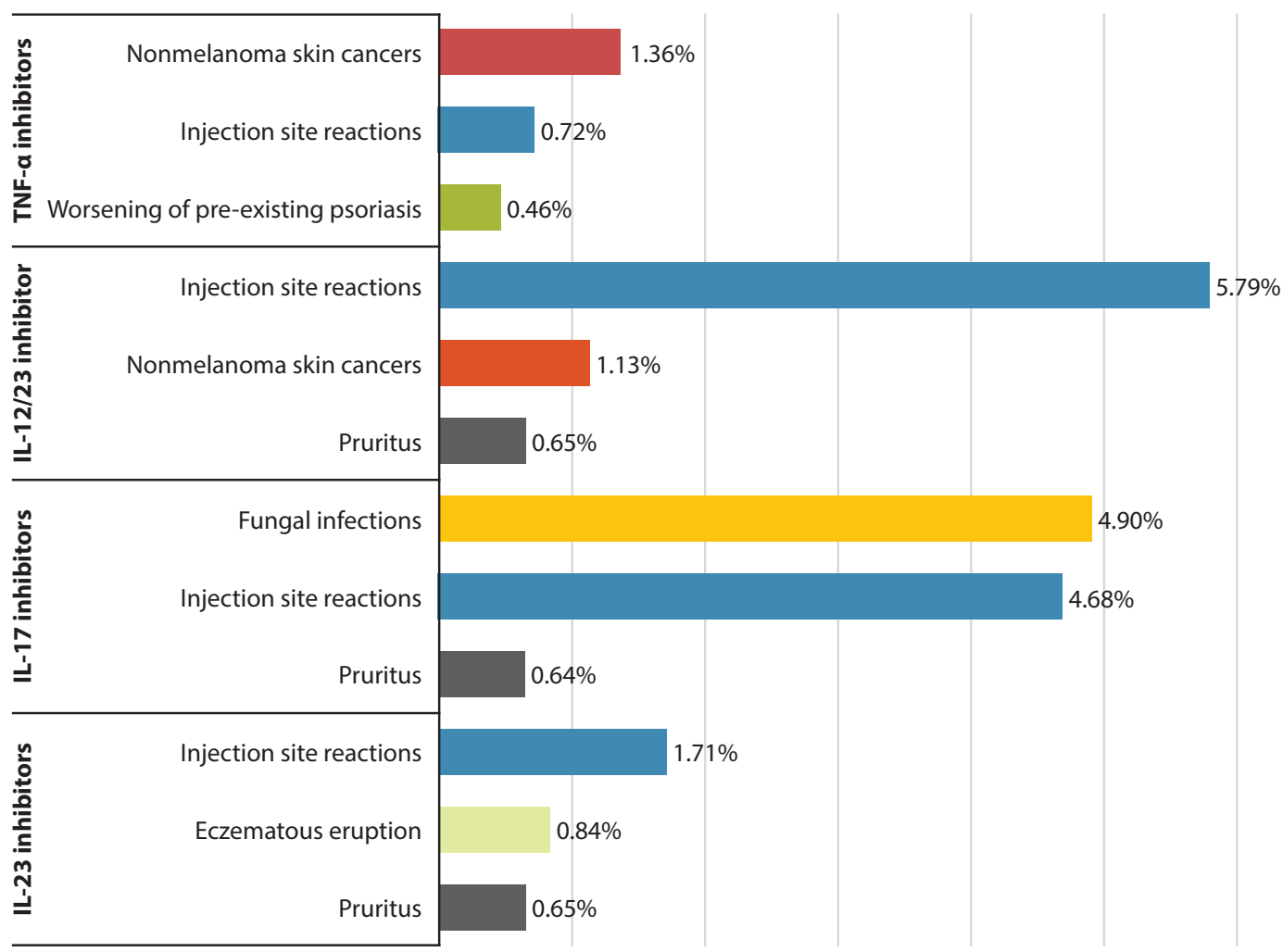

Figure 4. Three most common dermatologic adverse events by biologic class.

Bar graphs represent the rate of dermatologic adverse events (\%) by biologic class based on data from clinical and observational studies.

IL, interleukin; TNF, tumor necrosis factor 
Table 1. Summary of dermatologic adverse events during tumor necrosis factor- $\alpha$ inhibitors treatment.

\begin{tabular}{|c|c|c|c|c|c|c|c|c|}
\hline & \multicolumn{2}{|c|}{ Infliximab } & \multicolumn{2}{|c|}{ Adalimumab } & \multicolumn{2}{|c|}{ Etanercept } & \multicolumn{2}{|c|}{ Total } \\
\hline & $\mathrm{N}$ & $(\%)$ & $\mathrm{N}$ & $(\%)$ & $\mathrm{N}$ & $(\%)$ & $\mathrm{N}$ & $(\%)$ \\
\hline \multicolumn{9}{|l|}{ Allergic skin reactions } \\
\hline Injection site reactions & 2 & $(0.30)$ & 39 & $(0.34)$ & 71 & $(2.07)$ & 112 & $(0.72)$ \\
\hline Infusion reactions & 65 & $(9.69)$ & 0 & $(0.00)$ & 0 & $(0.00)$ & 65 & $(0.43)$ \\
\hline \multicolumn{9}{|l|}{ Hypersensitivity reactions } \\
\hline Non-anaphylactic reaction & 5 & $(0.57)$ & 6 & $(0.05)$ & 0 & $(0.00)$ & 11 & $(0.07)$ \\
\hline Anaphylaxis & 3 & $(0.45)$ & 1 & $(0.01)$ & 0 & $(0.00)$ & 4 & $(0.03)$ \\
\hline Nicolau syndrome & 0 & $(0.00)$ & 0 & $(0.00)$ & 1 & $(0.00)$ & 1 & $(0.00)$ \\
\hline \multicolumn{9}{|l|}{ Inflammatory skin diseases } \\
\hline Erythema & 2 & $(0.30)$ & 0 & $(0.00)$ & 0 & $(0.00)$ & 2 & $(0.01)$ \\
\hline Maculopapular rash & 0 & $(0.00)$ & 2 & $(0.00)$ & 0 & $(0.00)$ & 2 & $(0.00)$ \\
\hline Urticaria & 11 & $(1.49)$ & 2 & $(0.01)$ & $1^{\text {a }}$ & $(0.00)$ & 14 & $(0.07)$ \\
\hline $\begin{array}{l}\text { Intertriginous and flexural } \\
\text { exanthema }\end{array}$ & 1 & $(0.00)$ & 0 & $(0.00)$ & 0 & $(0.00)$ & 1 & $(0.00)$ \\
\hline Acute generalized skin eruption & 0 & $(0.00)$ & 2 & $(0.00)$ & 1 & $(0.00)$ & 3 & $(0.00)$ \\
\hline \multicolumn{9}{|l|}{ Eczema } \\
\hline Eczematous eruption & 3 & $(0.45)$ & 0 & $(0.00)$ & 0 & $(0.00)$ & 3 & $(0.02)$ \\
\hline Contact dermatitis & 3 & $(0.45)$ & 0 & $(0.00)$ & 0 & $(0.00)$ & 3 & $(0.02)$ \\
\hline Lichen simplex chronicus & 1 & $(0.00)$ & 0 & $(0.00)$ & 0 & $(0.00)$ & 1 & $(0.00)$ \\
\hline \multicolumn{9}{|l|}{ Psoriasis } \\
\hline $\begin{array}{l}\text { Worsening of pre-existing } \\
\text { psoriasis }\end{array}$ & 10 & $(1.49)$ & 50 & $(0.41)$ & 14 & $(0.42)$ & 74 & $(0.46)$ \\
\hline Paradoxical psoriasis & 3 & $(0.00)$ & 6 & $(0.00)$ & 2 & $(0.00)$ & 11 & $(0.00)$ \\
\hline Psoriasiform eruption & 0 & $(0.00)$ & 1 & $(0.00)$ & 0 & $(0.00)$ & 1 & $(0.00)$ \\
\hline $\begin{array}{l}\text { Other inflammatory skin } \\
\text { diseases }\end{array}$ & 5 & $(0.60)$ & 3 & $(0.00)$ & 7 & $(0.00)$ & 15 & $(0.03)$ \\
\hline \multicolumn{9}{|l|}{ Skin infections } \\
\hline Fungal infections & 6 & $(0.89)$ & 8 & $(0.07)$ & 2 & $(0.00)$ & 16 & $(0.09)$ \\
\hline Viral infections & 15 & $(2.24)$ & 0 & $(0.00)$ & 16 & $(0.48)$ & 31 & $(0.20)$ \\
\hline Bacterial infections & 9 & $(0.75)$ & 27 & $(0.24)$ & 24 & $(0.66)$ & 60 & $(0.35)$ \\
\hline Cutaneous leishmaniasis & 1 & $(0.00)$ & 0 & $(0.00)$ & 0 & $(0.00)$ & 1 & $(0.00)$ \\
\hline Unspecified skin infection & 1 & $(0.00)$ & 0 & $(0.00)$ & 0 & $(0.00)$ & 1 & $(0.00)$ \\
\hline \multicolumn{9}{|l|}{ Skin neoplasms } \\
\hline $\begin{array}{l}\text { Benign neoplasms/eruptive } \\
\text { naevi/pseudolymphoma }\end{array}$ & 3 & $(0.00)$ & 2 & $(0.00)$ & 1 & $(0.00)$ & 6 & $(0.00)$ \\
\hline \multicolumn{9}{|l|}{ Malignant neoplasms } \\
\hline Nonmelanoma skin cancers & 16 & $(0.60)$ & 138 & $(1.20)$ & 77 & $(2.04)$ & 231 & (1.36) \\
\hline Melanoma & 1 & $(0.15)$ & 13 & $(0.11)$ & 1 & $(0.00)$ & 15 & $(0.09)$ \\
\hline
\end{tabular}


Table 1. (Continued)

\begin{tabular}{lccccccccc} 
& \multicolumn{2}{c}{ Infliximab } & \multicolumn{2}{c}{ Adalimumab } & \multicolumn{2}{c}{ Etanercept } & \multicolumn{2}{c}{ Total } \\
\cline { 2 - 9 } & $\mathrm{N}$ & $(\%)$ & $\mathrm{N}$ & $(\%)$ & $\mathrm{N}$ & $(\%)$ & $\mathrm{N}$ & $(\%)$ \\
\hline Miscellaneous & 22 & $(3.28)$ & 0 & $(0.00)$ & 0 & $(0.00)$ & 22 & $(0.14)$ \\
\hline Pruritus & 3 & $(0.45)$ & 0 & $(0.00)$ & 9 & $(0.27)$ & 12 & $(0.08)$ \\
Acne & 0 & $(0.00)$ & 2 & $(0.00)$ & 0 & $(0.00)$ & 2 & $(0.00)$ \\
Sarcoidosis & $1^{\mathrm{b}}$ & $(0.00)$ & $1^{\mathrm{c}}$ & $(0.00)$ & $2^{\mathrm{c}}$ & $(0.00)$ & 4 & $(0.00)$ \\
\hline Pigmentary disorders & & & & & & & & & \\
\hline
\end{tabular}

The number of reported cases $(\mathrm{N})$ was calculated based on data from all types of studies while the percentage (\%) was calculated based on data from clinical and observational studies.

a 1 figurate urticaria ${ }^{45}$

b 1 vitiligo ${ }^{25}$

c 3 lentiginous hyperpigmentation ${ }^{46,47}$

Herpes zoster, herpes simplex, molluscum contagiosum, and skin papilloma were observed in patients treated with infliximab and etanercept (Supplementary Table 2). Hu et al., ${ }^{19}$ demonstrated that molluscum contagiosum attenuates TNF- $\alpha$-mediated host immune killing mechanisms; therefore, receiving TNF- $\alpha$ inhibitors may compromise TNF- $\alpha$-mediated antiviral defenses. In contrast, a recent meta-analysis of cohort studies showed no significantly increased risk of herpes zoster infection among psoriatic patients treated with infliximab, adalimumab, and etanercept. ${ }^{20}$

Inflammatory skin diseases that develop after treatment with TNF- $\alpha$ inhibitors have also been reported. Most of these cases were worsening of pre-existing psoriasis, paradoxical psoriasis, and psoriasiform eruption in 86 patients. There is a hypothesis that the blockage of TNF- $\alpha$ allows an increased and uncontrolled production of type 1 interferons (IFNs) by plasmacytoid DCs, which may induce and worsen psoriasiform lesions. ${ }^{21}$ TNF- $\alpha$ inhibitors may also induce and worsen psoriatic skin lesions in approximately $0.6 \%$ to $5.3 \%$ of patients. Crohn's disease and rheumatoid arthritis were the most common underlying diseases, and they were also reported in patients with psoriasis and psoriatic arthritis. These paradoxical psoriatic eruptions sometimes manifest in initially unaffected skin and may exhibit a new or different morphology from their original presentation of psoriasis. For example, patients with a history of plaque or guttate psoriasis may develop pustular lesions after TNF- $\alpha$ inhibitor therapy. ${ }^{21}$ The patients who discontinued TNF inhibitor therapy had the greatest resolution of symptoms (47.4\%) compared with those who switched to a different TNF agent (36.7\%) or continued therapy $(32.9 \%) .22$

Two cases of sarcoidosis were reported during adalimumab treatment and 1 case of vitiligo developed after 14 weeks of infliximab therapy. These rare paradoxical skin reactions could be associated with the activation of specific autoreactive T-cells due to cytokine imbalance following TNF- $\alpha$ inhibitors. $^{23-25}$

\section{IL-12/23 inhibitor}

Ustekinumab suppresses psoriasis through IL-12- and IL-23-mediated inflammation. Unlike TNF- $\alpha$ inhibitors, the target site of action (the subunit p40 of IL-12 and IL-23) is specific to the IL-12/Th1 pathway and IL-23/Th17 pathway. ${ }^{4}$

Comparing across biologic classes, the IL-12/23 inhibitor had the highest incidence of allergic skin reactions (6.25\%) consisting of ISRs $(5.79 \%)$ and non-anaphylactic reactions $(0.46 \%)$ (Table 2). Our reported incidence of ISRs was higher than those previously reported (1-2\%). ${ }^{13}$ Interestingly, the incidence of ISRs during ustekinumab administration was the second highest among all included biologics, only lower than that of ixekizumab (9.38\%), although ustekinumab is a fully human monoclonal antibody without a known allergenic potential vehicle component. Regarding the mechanism of action, ISRs can be divided into two groups: irritative reactions and allergic reactions to the ingredients or to the drug itself. It is plausible that the effect might be caused by irritative reactions. Causes of irritative reactions described in previous literature were inappropriate injection techniques, injection close to a blood vessel, the chemical and physical properties of the injected drug, and a reaction to the vehicle component. ${ }^{3,13,26}$ However, the incidence rate of ISRs was known to be highest in TNF-alpha inhibitors which is inconsistent with our study. Further studies are needed to provide evidence of the incidence rate of ISRs.

Skin neoplasms (1.26\%) were the second most frequently reported dermatologic AEs during ustekinumab treatment. NMSCs had a major contribution. The incidence of NMSCs in patients treated with ustekinumab ranked as the third highest rate following etanercept (2.04\%) and adalimumab (1.20\%). The most common type of NMSC was basal cell carcinoma (41 patients) followed by squamous cell carcinoma (12 patients), which corresponds to previous findings. ${ }^{27} \mathrm{Nev}-$ ertheless, ustekinumab administration was not associated with increased malignancy risk. ${ }^{3,8,28}$ 
Table 2. Summary of dermatologic adverse events during interleukin 12 and interleukin 23 inhibitor treatment.

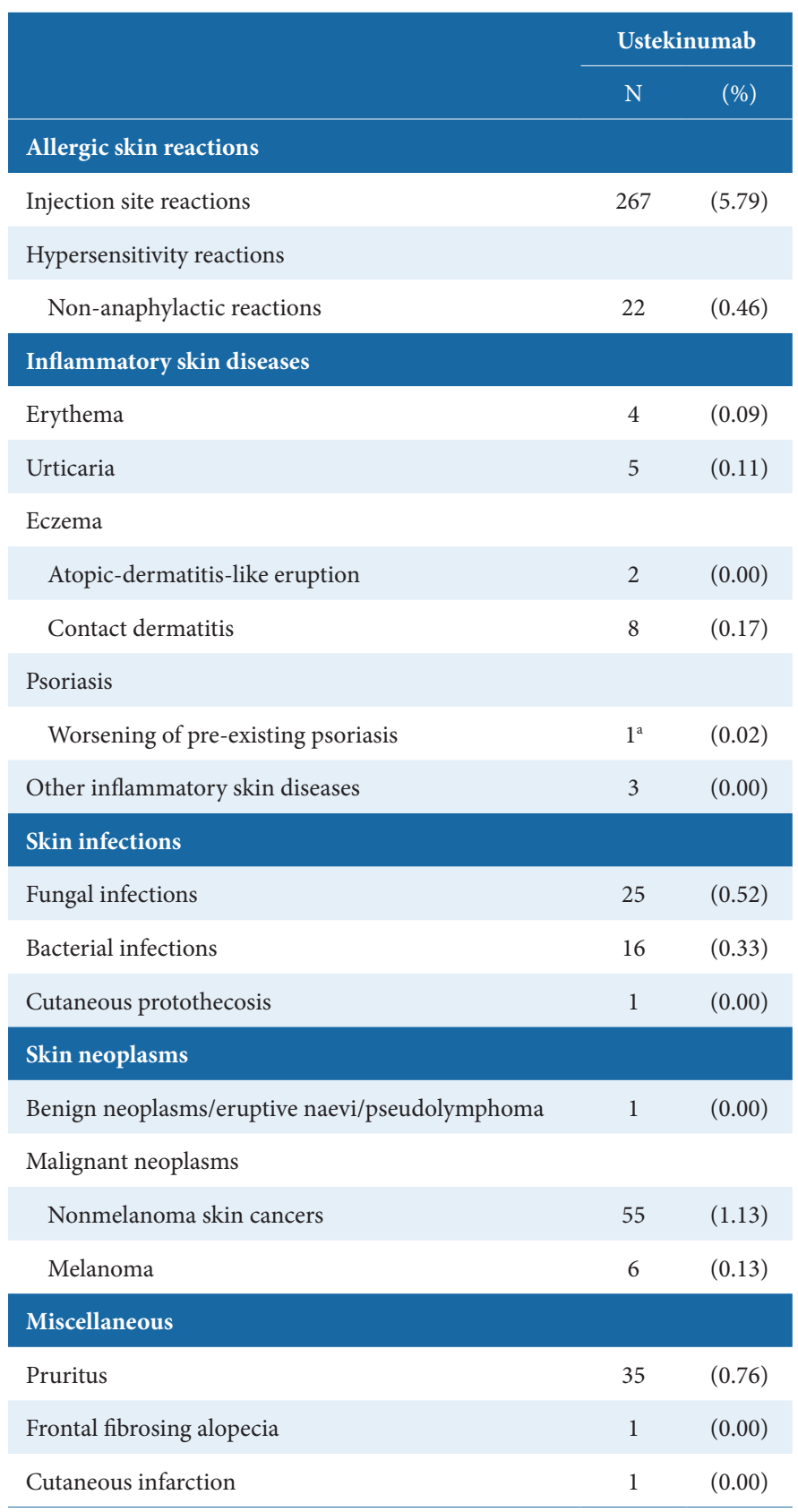

The number of reported cases $(\mathrm{N})$ was calculated based on data from all types of studies while the percentage (\%) was calculated based on data from clinical and observational studies.

a 1 pustular psoriasis. ${ }^{48}$
The rate of skin infections in patients treated with ustekinumab was $0.85 \%$. No viral infection was reported. IL-12 and IL-23 are essential cytokines for immunity. IL-12 is responsible for the differentiation of naïve Th cells to Th1 cells, which initiates and expands inflammatory reactions. IL-23 acts early in the inflammatory cascade in response to microbial products and inflammatory cytokines and promotes Th17 differentiation. Th17 cells produce several proinflammatory cytokines and activate further downstream inflammatory responses. Hence, IL-23 is essential not only for early local immunity but also for innate and adaptive immune responses. Blockade of the cytokines IL-12 and IL-23 can disrupt the activation of immune and inflammatory reactions. ${ }^{29}$ Therefore, skin infections following the use of ustekinumab could be postulated (details provided in Supplementary Table 3).

Reports of 2 atopic-dermatitis-like eruptions and 1 subacute cutaneous lupus erythematosus (SCLE) supported the possibility of Th1/Th2 imbalance following IL-12/23 inhibitor. The inhibition of IL-12 and IL-23 cytokines may shift T-cell differentiation toward the opposing Th2 pathway, resulting in exaggerated Th2 and Th22 cell responses. Consequently, atopic-dermatitis-like eruption, a Th2-mediated skin disease, can develop. ${ }^{30-32}$ Tierney et al., ${ }^{33}$ proposed that redundant Th22 production causes increased TNF- $\alpha$ through IL-6, which can lead to several inflammatory and autoimmune diseases, including SCLE.

\section{IL-17 inhibitors}

The IL-17 family consists of 5 members (IL-17A to IL17F). In psoriatic lesions, significant upregulation of IL-17A, $\mathrm{C}$, and $\mathrm{F}$ was demonstrated. IL-17A and IL-17F, produced mainly by Th17 cells and other immune cells (e.g., neutrophils, mast cells, natural killer cells, and lymphoid tissue-inducer cells), stimulate keratinocytes to produce proinflammatory cytokines and chemokines. Due to its high biological activity, IL-17A is a key cytokine contributing to psoriasis pathogenesis. $^{34-36}$

The early introduced IL-17 inhibitors secukinumab and ixekizumab selectively bind and neutralize IL-17A. Brodalumab interferes with IL-17 through IL-17 receptor A subunit (IL-17RA) blockade, which leads to the blockade of IL-17A, IL-17A/F, IL-17F, IL17-C, and IL-17E. The target sites of bimekizumab (FDA approval pending) are IL-17A and IL-17F. ${ }^{4}$

Allergic skin reactions, skin infections, and inflammatory skin diseases were commonly reported (Figure 3). Concerning allergic skin reactions, most of them were ISRs. In the present review, the highest incidence of reported ISRs was observed in patients treated with ixekizumab (9.38\%) (Table 3). A previous study revealed that the highest incidence rate of ISRs was reported in etanercept (2.97-37\%), followed by adalimumab (5-20\%) and ixekizumab (13-17\%). The mechanisms of injection site reactions following different biologics can be multifactorial, nonspecific, immunologic, and nonimmunologic factors, such as volume, temperature, $\mathrm{pH}$, speed of injection, needle size, injection techniques, and location of surrounding blood vessels. A recent study reported that the reactions from ixekizumab were generally mild-to-moderate in severity, resolved spontaneously without concomitant treatment, and did not require treatment discontinuation..$^{13,26}$ 
Table 3. Summary of dermatologic adverse events during interleukin 17 inhibitors treatment.

\begin{tabular}{|c|c|c|c|c|c|c|c|c|c|c|}
\hline & \multicolumn{2}{|c|}{ Secukinumab } & \multicolumn{2}{|c|}{ Ixekizumab } & \multicolumn{2}{|c|}{ Brodalumab } & \multicolumn{2}{|c|}{ Bimekizumab } & \multicolumn{2}{|c|}{ Total } \\
\hline & $\mathbf{N}$ & $(\%)$ & $\mathbf{N}$ & $(\%)$ & $\mathbf{N}$ & $(\%)$ & $\mathbf{N}$ & $(\%)$ & $\mathbf{N}$ & $(\%)$ \\
\hline \multicolumn{11}{|l|}{ Allergic skin reactions } \\
\hline Injection site reactions & 11 & $(0.35)$ & 316 & $(9.38)$ & 145 & $(5.53)$ & 3 & $(0.30)$ & 475 & $(4.68)$ \\
\hline \multicolumn{11}{|l|}{ Hypersensitivity reactions } \\
\hline Non-anaphylactic reactions & 12 & $(0.35)$ & 47 & $(1.39)$ & $2^{\mathrm{a}}$ & $(0.08)$ & 0 & $(0.00)$ & 61 & $(0.59)$ \\
\hline Anaphylaxis & 1 & $(0.03)$ & 0 & $(0.00)$ & 1 & $(0.04)$ & 0 & $(0.00)$ & 2 & $(0.02)$ \\
\hline \multicolumn{11}{|l|}{ Inflammatory skin diseases } \\
\hline Papular rash & 0 & $(0.00)$ & 0 & $(0.00)$ & 1 & $(0.04)$ & 0 & $(0.00)$ & 1 & $(0.01)$ \\
\hline Pustular rash & 0 & $(0.00)$ & 0 & $(0.00)$ & 0 & $(0.00)$ & 1 & $(0.10)$ & 1 & $(0.01)$ \\
\hline Urticaria & 5 & $(0.16)$ & 0 & $(0.00)$ & 5 & $(0.19)$ & 0 & $(0.00)$ & 10 & $(0.10)$ \\
\hline Dermatitis & 4 & $(0.13)$ & 0 & $(0.00)$ & 0 & $(0.00)$ & 0 & $(0.00)$ & 4 & $(0.04)$ \\
\hline Dermatitis acneiform & 3 & $(0.10)$ & 0 & $(0.00)$ & 0 & $(0.00)$ & 0 & $(0.00)$ & 3 & $(0.03)$ \\
\hline Photosensitive cutaneous eruption & 0 & $(0.00)$ & 1 & $(0.00)$ & 0 & $(0.00)$ & 0 & $(0.00)$ & 1 & $(0.00)$ \\
\hline Unspecified rash & 3 & $(0.10)$ & 0 & $(0.00)$ & 0 & $(0.00)$ & 0 & $(0.00)$ & 3 & $(0.03)$ \\
\hline \multicolumn{11}{|l|}{ Eczema } \\
\hline Eczematous eruption & 33 & $(1.05)$ & 1 & $(0.03)$ & 3 & $(0.11)$ & 0 & $(0.00)$ & 37 & $(0.36)$ \\
\hline Atopic-dermatitis-like eruption & 7 & $(0.19)$ & 5 & $(0.15)$ & 0 & $(0.00)$ & 0 & $(0.00)$ & 12 & $(0.11)$ \\
\hline Contact dermatitis & 12 & $(0.38)$ & 0 & $(0.00)$ & 1 & $(0.04)$ & 0 & $(0.00)$ & 13 & $(0.13)$ \\
\hline Dyshidrotic eczema & 1 & $(0.00)$ & 0 & $(0.00)$ & 0 & $(0.00)$ & 0 & $(0.00)$ & 1 & $(0.00)$ \\
\hline \multicolumn{11}{|l|}{ Psoriasis } \\
\hline $\begin{array}{l}\text { Worsening of pre-existing } \\
\text { psoriasis }\end{array}$ & 22 & $(0.70)$ & 0 & $(0.00)$ & $2^{\mathrm{b}}$ & $(0.08)$ & 12 & $(1.19)$ & 36 & $(0.35)$ \\
\hline Paradoxical psoriasis & 1 & $(0.00)$ & 0 & $(0.00)$ & 2 & $(0.00)$ & 0 & $(0.00)$ & 3 & $(0.00)$ \\
\hline Psoriasiform eruption & 1 & $(0.03)$ & 5 & $(0.12)$ & 0 & $(0.00)$ & 0 & $(0.00)$ & 6 & $(0.05)$ \\
\hline Other inflammatory skin diseases & 3 & $(0.00)$ & 0 & $(0.00)$ & 1 & $(0.04)$ & 1 & $(0.10)$ & 5 & $(0.02)$ \\
\hline \multicolumn{11}{|l|}{ Skin infections } \\
\hline Fungal infections & 91 & $(2.89)$ & 78 & $(2.31)$ & 161 & $(6.15)$ & 168 & $(16.62)$ & 498 & $(4.90)$ \\
\hline Viral infections & 0 & $(0.00)$ & 2 & $(0.06)$ & 1 & $(0.04)$ & 0 & $(0.00)$ & 3 & $(0.03)$ \\
\hline Bacterial infections & 2 & $(0.03)$ & 0 & $(0.00)$ & 9 & $(0.27)$ & 0 & $(0.00)$ & 11 & $(0.08)$ \\
\hline \multicolumn{11}{|l|}{ Skin neoplasms } \\
\hline \multicolumn{11}{|l|}{ Malignant neoplasms } \\
\hline Nonmelanoma skin cancers & 12 & $(0.32)$ & 2 & $(0.06)$ & 0 & $(0.00)$ & 4 & $(0.40)$ & 18 & $(0.16)$ \\
\hline Melanoma & 3 & $(0.10)$ & 1 & $(0.03)$ & 0 & $(0.00)$ & 1 & $(0.10)$ & 5 & $(0.05)$ \\
\hline \multicolumn{11}{|l|}{ Miscellaneous } \\
\hline Pruritus & 59 & $(1.87)$ & 0 & $(0.00)$ & 6 & $(0.23)$ & 0 & $(0.00)$ & 65 & $(0.64)$ \\
\hline Sarcoidosis & 0 & $(0.00)$ & 0 & $(0.00)$ & 1 & $(0.04)$ & 0 & $(0.00)$ & 1 & $(0.01)$ \\
\hline
\end{tabular}

The number of reported cases $(\mathrm{N})$ was calculated based on data from all types of studies while the percentage (\%) was calculated based on data from clinical and observational studies.

DFSP, Dermatofibrosarcoma protuberans; LE, lupus erythematosus; SLE, Systematic lupus erythematosus

a 2 angioedema ${ }^{49}$

b 2 erythrodermic psoriasis ${ }^{49}$ 
The rate of skin infections (5.01\%) was remarkably high among biologic classes, mainly driven by fungal infections $(4.90 \%)$, followed by bacterial infections $(0.08 \%)$. Fungal infections comprised $492(4.85 \%)$ mucocutaneous candidiasis, $4(0.04 \%)$ cutaneous dermatophytosis, and 2 (0.02\%) unspecified fungal infections. Bacterial infections included furunculosis, abscess, erysipelas, cellulitis, and necrotizing fasciitis (Supplementary Table 4). In addition to its role in psoriasis immunopathogenesis, IL-17 acts as a proinflammatory cytokine during the innate and adaptive immune response against mucosal and cutaneous Candida albicans infection. Therefore, the blockade of IL-17 can lead to defects in local defensive mechanisms, resulting in increased susceptibility to Candida infection. Moreover, IL-17 is associated with humoral immunity by promoting B cell isotype switching and germinal center formation. ${ }^{37,38}$ Consequently, various bacterial, viral, and fungal infections could occur following IL-17 inhibitor treatment. In this review, most infections following IL-17 inhibitors were mucocutaneous candidiasis (4.85\%), followed by cellulitis $(0.07 \%) .{ }^{39,40}$ A higher rate of skin infections was observed in patients treated with bimekizumab (16.62\%) and brodalumab $(6.15 \%)$ which could be explained by the boarder effects of these 2 biologics on IL-17 members.

Eczematous and atopic-dermatitis-like eruptions were observed in $1.24 \%, 0.18 \%$, and $0.11 \%$ of patients treated with secukinumab, ixekizumab, and brodalumab, respectively. The number of eczematous eruptions and atopic-dermatitis-like eruptions reported during IL-17 inhibitor treatment was higher than those during treatment with drugs from other biologic classes. Several theories have been proposed for this phenomenon. Immune or cytokine imbalance syndromes, or the type $\gamma$ reaction described by Pichler, ${ }^{41}$ could be used to clarify the occurrence of eczema. Under normal circumstances, the immune system and Th1/Th2 balance are well balanced. Thus, the blockade of IL-17, an effector cytokine of Th17, could shift toward a Th-2-dominated immune response that can present as eczematous eruptions or atopic-dermatitis-like eruptions in psoriatic patients treated with IL-17 inhibitors. ${ }^{32}$ Furthermore, it has been hypothesized that a defect in host defenses against Staphylococcus aureus skin infection following IL-17 inhibitors may be involved since atopic eczema lesions are often infiltrated by Staphylococcus aureus colonization. ${ }^{42}$ Regarding the findings of the present review, eczematous eruptions and atopic-dermatitis-like eruptions were more frequently observed in patients treated with secukinumab and ixekizumab than in those treated with brodalumab, which can be explained by the mechanism proposed by Caldarola G. et al. ${ }^{43}$ Secukinumab and ixelizumab selectively block IL-17A, which might induce the overexpression of other IL-17 members. Increasing IL-17C levels could lead to overstimulation keratinocytes, which may be associated with Th2-driven inflammatory skin disease (i.e., atopic dermatitis).

Compared to other biologic classes, IL-17 inhibitors had the lowest incidence of skin neoplasms $(0.21 \%)$. No definite evidence supported the increased malignancy risk associated with IL-17 inhibitors. ${ }^{3}$

\section{IL-23 inhibitors}

Recent knowledge from genetic analyses revealed that the IL-23/Th17 axis is the dominant pathogenic pathway for psoriasis. ${ }^{2}$ Novel biologics, i.e., guselkumab, tildrakizumab, and risankizumab, were developed to target only the IL-23/Th17 axis via subunit p19 of IL-23. In contrast to ustekinumab, the IL-12/Th1 axis is not affected, which reduces some potential AEs. ${ }^{3}$

The overall number of dermatologic AEs in patients treated with IL-23 inhibitors was low compared to other biologic classes, which may be explained by the fact that IL-23 inhibitors are the most recent class of biologics. Allergic skin reactions $(2.32 \%)$ and inflammatory skin diseases $(2.32 \%)$ were the most common cutaneous adverse effects, followed by skin infections (1.10\%) and skin neoplasms (0.95\%) (Figure 3).

Comparing across biologic classes, the incidence of inflammatory skin diseases $(2.32 \%)$ dominated in patients treated with IL-23 inhibitors, especially eczematous eruption (Table 4). As IL-23 is an upstream cytokine regulator in the IL-23/ Th17 axis, the blockade of IL-23 leads to IL-17A and IL-17F suppression. ${ }^{44}$ Therefore, the occurrence of eczematous eruption following IL-23 inhibitors could be explained by Th1/Th2 imbalance (as mentioned in the IL-17 inhibitor section). ${ }^{32}$

Despite an intact Th1 response, skin infections were reported in $1.10 \%$ of patients treated with IL-23 inhibitors (0.08\% fungal infections, $0.53 \%$ viral infections, $0.46 \%$ bacterial infections, and $0.04 \%$ unspecified skin infections). It is difficult to describe any relevant information due to limited detailed data in the included studies.

The rate of skin neoplasms following IL-23 inhibitor treatment was $0.95 \%$. Benign skin neoplasms were more frequently reported than malignant neoplasms (details provided in Supplementary Table 5); however, the relationship between IL-23 and benign skin neoplasms has not been elucidated. Regarding malignant neoplasms, a previous study by Ergen et al., ${ }^{27}$ reported malignancies in clinical trials of IL-12/23 and IL-23 inhibitors in patients with moderate-to-severe psoriasis receiving active treatment with IL-12/23 or IL-23 inhibitors and found that NMSCs were the most frequently reported malignancies. Furthermore, they reviewed the malignancy data from animal models of IL-23 deficiency and discovered conflicting data. More studies are needed to clarify this finding.

To the best of our knowledge, this review is the first to present an overview of dermatologic AEs related to FDA-approved and FDA approval-pending (as of July 2021) biologics used for moderate-to-severe psoriasis, as well as emerging dermatologic AEs, and compare those across different biologic classes by classifying the impacts into five groups, in addition to postulating the mechanism that may explain individual phenomena. Data were categorized per biologic group with the intention of facilitating use in clinical practice and to illustrate a class effect. However, our study contains some limitations. First, the reported dermatological AEs from case series and case reports were unable to be included in the incidence calculation, which may affect the incidence reported here. However, they were counted and presented as the number of cases $(\mathrm{N})$ to obtain all reported dermatologic AEs. 
Table 4. Summary of dermatologic adverse events during interleukin 23 inhibitors treatment.

\begin{tabular}{|c|c|c|c|c|c|c|c|c|}
\hline & \multicolumn{2}{|c|}{ Guselkumab } & \multicolumn{2}{|c|}{ Tildrakizumab } & \multicolumn{2}{|c|}{ Risankizumab } & \multicolumn{2}{|c|}{ Total } \\
\hline & $\mathbf{N}$ & (\%) & $\mathbf{N}$ & $(\%)$ & $\mathbf{N}$ & $(\%)$ & $\mathbf{N}$ & $(\%)$ \\
\hline \multicolumn{9}{|l|}{ Allergic skin reactions } \\
\hline Injection site reactions & 35 & (2.99) & 8 & $(1.50)$ & 2 & $(0.22)$ & 45 & $(1.71)$ \\
\hline \multicolumn{9}{|l|}{ Hypersensitivity reactions } \\
\hline Non-anaphylactic reactions & 0 & $(0.00)$ & 3 & $(0.56)$ & 13 & $(1.40)$ & 16 & $(0.61)$ \\
\hline \multicolumn{9}{|l|}{ Inflammatory skin diseases } \\
\hline Papular rash & 0 & $(0.00)$ & 0 & $(0.00)$ & 1 & $(0.11)$ & 1 & $(0.04)$ \\
\hline Urticaria & 1 & $(0.09)$ & 9 & $(1.69)$ & 0 & $(0.00)$ & 10 & $(0.38)$ \\
\hline Heat rash & 1 & $(0.09)$ & 0 & $(0.00)$ & 0 & $(0.00)$ & 1 & $(0.04)$ \\
\hline Dermatitis & 2 & $(0.17)$ & 0 & $(0.00)$ & 0 & $(0.00)$ & 2 & $(0.08)$ \\
\hline \multicolumn{9}{|l|}{ Eczema } \\
\hline Eczematous eruption & 1 & $(0.09)$ & 21 & (3.95) & 0 & $(0.00)$ & 22 & $(0.84)$ \\
\hline Contact dermatitis & 0 & $(0.00)$ & 10 & $(1.88)$ & 5 & $(0.54)$ & 15 & $(0.57)$ \\
\hline \multicolumn{9}{|l|}{ Psoriasis } \\
\hline $\begin{array}{l}\text { Worsening of pre-existing } \\
\text { psoriasis }\end{array}$ & 1 & $(0.09)$ & 8 & $(1.50)$ & 1 & $(0.11)$ & 2 & $(0.38)$ \\
\hline \multicolumn{9}{|l|}{ Skin infections } \\
\hline Fungal infections & 1 & $(0.09)$ & 0 & $(0.00)$ & 1 & $(0.11)$ & 2 & $(0.08)$ \\
\hline Viral infections & 1 & $(0.09)$ & 10 & $(1.88)$ & 3 & $(0.32)$ & 14 & $(0.53)$ \\
\hline Bacterial infections & 5 & $(0.43)$ & 4 & $(0.75)$ & 3 & $(0.32)$ & 12 & $(0.46)$ \\
\hline Unspecified skin infection & 1 & $(0.09)$ & 0 & $(0.00)$ & 0 & $(0.00)$ & 1 & $(0.04)$ \\
\hline \multicolumn{9}{|l|}{ Skin neoplasms } \\
\hline $\begin{array}{l}\text { Benign neoplasms/eruptive naevi/ } \\
\text { pseudolymphoma }\end{array}$ & 0 & $(0.00)$ & 14 & (2.63) & 0 & $(0.00)$ & 14 & $(0.53)$ \\
\hline \multicolumn{9}{|l|}{ Malignant neoplasms } \\
\hline Nonmelanoma skin cancers & 2 & $(0.17)$ & 0 & $(0.00)$ & 8 & $(0.86)$ & 10 & $(0.38)$ \\
\hline Melanoma & 0 & $(0.00)$ & 1 & $(0.19)$ & 0 & $(0.00)$ & 1 & $(0.04)$ \\
\hline \multicolumn{9}{|l|}{ Miscellaneous } \\
\hline Pruritus & 3 & $(0.26)$ & 13 & (2.44) & 1 & $(0.11)$ & 17 & $(0.65)$ \\
\hline Lymphoedema & 0 & $(0.00)$ & 1 & (0.19) & 0 & $(0.00)$ & 1 & $(0.04)$ \\
\hline
\end{tabular}

The number of reported cases $(\mathrm{N})$ was calculated based on data from all types of studies while the percentage (\%) was calculated based on data from clinical and observational studies. 
In addition, unspecified/incomplete data regarding the type of biologic and dermatologic AEs can affect the incidence and the number of reported cases. A large number of dermatologic AEs were observed and expected to rise in response to an increase in use of biologics for the treatment of psoriasis. Future studies are required to evaluate the incidence rate, identify definite mechanisms, and examine factors associated with these dermatologic AEs to foster effective treatment of psoriasis.

\section{Conclusions}

Dermatologic AEs are commonly observed during biologic therapies in patients with psoriasis. Certain AEs dominated in specific biologic classes, suggesting a class effect. Identifying definite mechanisms of these potential AEs is challenging yet could provide tremendous assistance in guiding the appropriate selection of biologics for use in treating psoriatic patients.

\section{Acknowledgements}

None.

\section{Conflict of interest}

The authors declared no conflict-of-interest. Figure 2 was created with BioRender.com.

\section{Source of funding with grant numbers} work.

The authors received no specific funding for the present

\section{Author contributions}

- PP and PR analyzed and interpreted the data and were the major contributor in writing the manuscript.

- $\mathrm{KN}$ was the minor contributor in writing the manuscript.

- All authors reviewed and approved the final manuscript.

\section{References}

1. Michalek IM, Loring B, John SM. A systematic review of worldwide epidemiology of psoriasis. J Eur Acad Dermatol Venereol. 2017;31(2): 205-12.

2. Mahil SK, Capon F, Barker JN. Update on psoriasis immunopathogenesis and targeted immunotherapy. Semin Immunopathol. 2016;38(1):11-27.

3. Menter A, Strober BE, Kaplan DH, Kivelevitch D, Prater EF, Stoff B, et al. Joint AAD-NPF guidelines of care for the management and treatment of psoriasis with biologics. J Am Acad Dermatol. 2019;80(4):1029-72.

4. Rønholt K, Iversen L. Old and New Biological Therapies for Psoriasis. Int J Mol Sci. 2017;18(11).

5. SKYRIZI (risankizumab-rzaa) injection, $75 \mathrm{mg} / 0.83 \mathrm{ml}$. North Chicago (IL): AbbVie, Inc.; 2019 Apr. Package insert. NDC 0074-2042-02.

6. Nardone B, Orrell KA, Vakharia PP, West DP. Skin cancer associated with commonly prescribed drugs: tumor necrosis factor alpha inhibitors (TNF-aIs), angiotensin-receptor blockers (ARBs), phosphodiesterase type 5 inhibitors (PDE5Is) and statins -weighing the evidence. Expert Opin Drug Saf. 2018;17(2):139-47.

7. Fagerli KM, Kearsley-Fleet L, Mercer LK, Watson K, Packham J, Symmons DPM, et al. Malignancy and mortality rates in patients with severe psoriatic arthritis requiring tumour-necrosis factor alpha inhibition: results from the British Society for Rheumatology Biologics Register. Rheumatology (Oxford). 2019;58(1):80-5.

8. Peleva E, Exton LS, Kelley K, Kleyn CE, Mason KJ, Smith CH. Risk of cancer in patients with psoriasis on biological therapies: a systematic review. Br J Dermatol. 2018;178(1):103-13.
9. Askling J, Fahrbach K, Nordstrom B, Ross S, Schmid CH, Symmons D. Cancer risk with tumor necrosis factor alpha (TNF) inhibitors: meta-analysis of randomized controlled trials of adalimumab, etanercept, and infliximab using patient level data. Pharmacoepidemiol Drug Saf. 2011;20(2):119-30.

10. Thielen AM, Kuenzli S, Saurat JH. Cutaneous adverse events of biological therapy for psoriasis: review of the literature. Dermatology. 2005;211(3):209-17.

11. Archier E, Devaux S, Castela E, Gallini A, Aubin F, Le Maître M, et al. Carcinogenic risks of psoralen UV-A therapy and narrowband UV-B therapy in chronic plaque psoriasis: a systematic literature review. J Eur Acad Dermatol Venereol. 2012;26 Suppl 3:22-31.

12. St Clair-Jones A, Prignano F, Goncalves J, Paul M, Sewerin P. Understanding and Minimising Injection-Site Pain Following Subcutaneous Administration of Biologics: A Narrative Review. Rheumatol Ther. 2020;7(4):741-57.

13. Thomaidou E, Ramot Y. Injection site reactions with the use of biological agents. Dermatol Ther. 2019;32(2):e12817.

14. Lichtenstein L, Ron Y, Kivity S, Ben-Horin S, Israeli E, Fraser GM, et al Infliximab-Related Infusion Reactions: Systematic Review. J Crohns Colitis. 2015;9(9):806-15.

15. Harris J, Keane J. How tumour necrosis factor blockers interfere with tuberculosis immunity. Clin Exp Immunol. 2010;161(1):1-9.

16. Wallis RS. Reactivation of latent tuberculosis by TNF blockade: the role of interferon gamma. J Investig Dermatol Symp Proc. 2007;12(1):16-21.

17. Mezouar S, Diarra I, Roudier J, Desnues B, Mege JL. Tumor Necrosis Factor-Alpha Antagonist Interferes With the Formation of Granulomatous Multinucleated Giant Cells: New Insights Into Mycobacterium tuberculosis Infection. Front Immunol. 2019;10:1947.

18. Winthrop KL, Chang E, Yamashita S, Iademarco MF, LoBue PA. Nontuberculous mycobacteria infections and anti-tumor necrosis factor-alpha therapy. Emerg Infect Dis. 2009;15(10):1556-61.

19. Hu S, Vincenz C, Buller M, Dixit VM. A novel family of viral death effector domain-containing molecules that inhibit both CD-95- and tumor necrosis factor receptor-1-induced apoptosis. J Biol Chem. 1997;272(15):9621-4.

20. Tang Z, Shen M, Chen X. Risk of Herpes Zoster Among Psoriasis Patients Taking Biologics: A Network Meta-Analysis of Cohort Studies. Front Med (Lausanne). 2021;8:665559.

21. Li SJ, Perez-Chada LM, Merola JF. TNF Inhibitor-Induced Psoriasis: Proposed Algorithm for Treatment and Management. J Psoriasis Psoriatic Arthritis. 2019;4(2):70-80.

22. Brown G, Wang E, Leon A, Huynh M, Wehner M, Matro R, et al. Tumor necrosis factor- $\alpha$ inhibitor-induced psoriasis: Systematic review of clinical features, histopathological findings, and management experience. J Am Acad Dermatol. 2017;76(2):334-41.

23. Lamrock E, Brown P. Development of cutaneous sarcoidosis during treatment with tumour necrosis alpha factor antagonists. Australas J Dermatol. 2012;53(4):e87-90.

24. Turkowski Y, Konnikov N, Mahalingam M. Necrotizing Granulomas in a Patient With Psoriasis and Sarcoidosis After Adalimumab-Medication -Induced Reaction or Reactivation of Latent Disease? Am J Dermatopathol. 2019;41(9):661-6.

25. Lu X, Gao Y, Ding Y. Vitiligo in a patient receiving infliximab for chronic plaque psoriasis. Dermatol Ther. 2019;32(3):e12917.

26. Corominas M, Gastaminza G, Lobera T. Hypersensitivity reactions to biological drugs. J Investig Allergol Clin Immunol. 2014;24(4):212-25; quiz $1 \mathrm{p}$ following 25.

27. Ergen EN, Yusuf N. Inhibition of interleukin-12 and/or interleukin-23 for the treatment of psoriasis: What is the evidence for an effect on malignancy? Exp Dermatol. 2018;27(7):737-47.

28. Fiorentino D, Ho V, Lebwohl MG, Leite L, Hopkins L, Galindo C, et al. Risk of malignancy with systemic psoriasis treatment in the Psoriasis Longitudinal Assessment Registry. J Am Acad Dermatol. 2017;77(5): 845-54.e5.

29. Ru Y, Ding X, Luo Y, Li H, Sun X, Zhou M, et al. Adverse Events Associated With Anti-IL-23 Agents: Clinical Evidence and Possible Mechanisms. Front Immunol. 2021;12:670398.

30. Guttman-Yassky E, Krueger JG, Lebwohl MG. Systemic immune mechanisms in atopic dermatitis and psoriasis with implications for treatment. Exp Dermatol. 2018;27(4):409-17.

31. Ishiuji Y, Umezawa Y, Asahina A, Fukuta H, Aizawa N, Yanaba K, et al Exacerbation of atopic dermatitis symptoms by ustekinumab in psoriatic patients with elevated serum immunoglobulin E levels: Report of two cases. J Dermatol. 2018;45(6):732-4. 
32. Al-Janabi A, Foulkes AC, Mason K, Smith CH, Griffiths CEM, Warren RB. Phenotypic switch to eczema in patients receiving biologics for plaque psoriasis: a systematic review. J Eur Acad Dermatol Venereol. 2020;34(7): 1440-8.

33. Tierney E, Kirthi S, Ramsay B, Ahmad K. Ustekinumab-induced subacute cutaneous lupus. JAAD Case Rep. 2019;5(3):271-3.

34. Akiyama S, Sakuraba A. Distinct roles of interleukin-17 and T helper 17 cells among autoimmune diseases. J Transl Autoimmun. 2021;4:100104.

35. Blauvelt A, Chiricozzi A. The Immunologic Role of IL-17 in Psoriasis and Psoriatic Arthritis Pathogenesis. Clin Rev Allergy Immunol. 2018; 55(3):379-90.

36. Kirkham BW, Kavanaugh A, Reich K. Interleukin-17A: a unique pathway in immune-mediated diseases: psoriasis, psoriatic arthritis and rheumatoid arthritis. Immunology. 2014;141(2):133-42.

37. McAleer JP, Kolls JK. Mechanisms controlling Th17 cytokine expression and host defense. J Leukoc Biol. 2011;90(2):263-70.

38. Khader SA, Gaffen SL, Kolls JK. Th17 cells at the crossroads of innate and adaptive immunity against infectious diseases at the mucosa. Mucosal Immunol. 2009;2(5):403-11.

39. Krishna S, Miller LS. Innate and adaptive immune responses against Staphylococcus aureus skin infections. Semin Immunopathol. 2012; 34(2):261-80.

40. Harder J, Gläser R, Schröder JM. Human antimicrobial proteins effectors of innate immunity. J Endotoxin Res. 2007;13(6):317-38.

41. Pichler WJ. Adverse side-effects to biological agents. Allergy. 2006;61(8): 912-20.

42. Eyerich S, Onken AT, Weidinger S, Franke A, Nasorri F, Pennino D, et al. Mutual antagonism of T cells causing psoriasis and atopic eczema. $\mathrm{N}$ Engl J Med. 2011;365(3):231-8.

43. Caldarola G, Pirro F, Di Stefani A, Talamonti M, Galluzzo M, D’Adamio $\mathrm{S}$, et al. Clinical and histopathological characterization of eczematous eruptions occurring in course of anti IL-17 treatment: a case series and review of the literature. Expert Opin Biol Ther. 2020;20(6):665-72.

44. Di Cesare A, Di Meglio P, Nestle FO. The IL-23/Th17 axis in the immunopathogenesis of psoriasis. J Invest Dermatol. 2009;129(6):1339-50.

45. Sessa M, Sullo MG, Mascolo A, Cimmaruta D, Romano F, Puca RV, et al. A case of figurate urticaria by etanercept. J Pharmacol Pharmacother. 2016;7(2):106-8.

46. Santos-Juanes J, Coto P, Mallo S, Galache C, Sánchez del Río J, Torre JC. Multiple lentigines confined to resolving psoriatic plaques in a patient treated with adalimumab. Dermatology. 2008;216(3):279.

47. Costa LA, Belinchón I, Betlloch I, Pérez-Crespo M, Mataix J. Multiple lentigines arising in resolving psoriatic plaques after treatment with etanercept. Dermatol Online J. 2008;14(1):11.

48. Youn SW, Tsai TF, Theng C, Choon SE, Wiryadi BE, Pires A, et al. The MARCOPOLO Study of Ustekinumab Utilization and Efficacy in a Real-World Setting: Treatment of Patients with Plaque Psoriasis in Asia-Pacific Countries. Ann Dermatol. 2016;28(2):222-31.

49. Lebwohl M, Strober B, Menter A, Gordon K, Weglowska J, Puig L, et al. Phase 3 Studies Comparing Brodalumab with Ustekinumab in Psoriasis. N Engl J Med. 2015;373(14):1318-28.

50. Reich K, Nestle FO, Papp K, Ortonne JP, Evans R, Guzzo C, et al. Infliximab induction and maintenance therapy for moderate-to-severe psoriasis: a phase III, multicentre, double-blind trial. Lancet. 2005;366(9494):1367-74.

51. Smith CH, Jackson K, Bashir SJ, Perez A, Chew AL, Powell AM, et al. Infliximab for severe, treatment-resistant psoriasis: a prospective, open -label study. Br J Dermatol. 2006;155(1):160-9.

52. Torii H, Nakagawa H. Infliximab monotherapy in Japanese patients with moderate-to-severe plaque psoriasis and psoriatic arthritis. A randomized, double-blind, placebo-controlled multicenter trial. J Dermatol Sci. 2010; 59(1):40-9.

53. Torii H, Nakano M, Yano T, Kondo K, Nakagawa H. Efficacy and safety of dose escalation of infliximab therapy in Japanese patients with psoriasis: Results of the SPREAD study. J Dermatol. 2017;44(5):552-9.

54. Antoniou C, Stefanaki I, Stratigos A, Moustou E, Vergou T, Stavropoulos P, et al. Infliximab for the treatment of psoriasis in Greece: 4 years of clinical experience at a single centre. Br J Dermatol. 2010;162(5):1117-23.

55. Antonio JR, Sanmiguel J, Cagnon GV, Augusto MS, Godoy MF, Pozetti EM. Infliximab in patients with psoriasis and other inflammatory diseases: evaluation of adverse events in the treatment of 168 patients. An Bras Dermatol. 2016;91(3):306-10.
56. Petridis A, Panagakis P, Moustou E, Vergou T, Kallidis P, Mandekou -Lefaki I, et al. A multicenter, prospective, observational study examining the impact of risk factors, such as BMI and waist circumference, on quality of life improvement and clinical response in moderate-to-severe plaque-type psoriasis patients treated with infliximab in routine care settings of Greece. J Eur Acad Dermatol Venereol. 2018;32(5):768-75.

57. Chen W, Ding Y, Lu J, Shi Y, Gao Y, Peng C. Efficacy and survival of infliximab in psoriasis patients: A single-center experience in China. Dermatol Ther. 2020;33(6):e14227.

58. Nguyen R, Braue A, Baker C, Foley P. Five-year experience with infliximab: Follow up of the product familiarisation program. Australas J Dermatol. 2016;57(4):300-6.

59. Conrad C, Di Domizio J, Mylonas A, Belkhodja C, Demaria O, Navarini AA, et al. TNF blockade induces a dysregulated type I interferon response without autoimmunity in paradoxical psoriasis. Nat Commun. 2018; 9(1):25.

60. Garcovich S, Burlando M, Rongioletti F, Garcovich A, Parodi A, Amerio P. Cutaneous drug eruption with an interface dermatitis pattern due to anti-tumour necrosis factor-alpha agents: a relevant class-effect. Acta Derm Venereol. 2010;90(3):311-2.

61. Molin S, Ruzicka T, Prinz JC. Borreliosis mimicking lupus-like syndrome during infliximab treatment. Clin Exp Dermatol. 2010;35(6):631-3.

62. De Simone C, Murri R, Maiorino A, Venier A, Caldarola G. Management of recurrent cutaneous abscesses during therapy with infliximab. Clin Ther. 2011;33(12):1993-6.

63. Teixeira FM, Vasconcelos LM, Rola Cde A, Prata de Almeida TL, Valença JT Jr, Nagao-Dias AT. Secondary leprosy infection in a patient with psoriasis during treatment with infliximab. J Clin Rheumatol. 2011;17(5): 269-71.

64. Imafuku S, Ito K, Nakayama J. Cutaneous pseudolymphoma induced by adalimumab and reproduced by infliximab in a patient with arthropathic psoriasis. Br J Dermatol. 2012;166(3):675-8.

65. Aslam A, Green RL, Motta L, Ghrew M, Griffiths CE, Warren RB Cutaneous Mycobacterium haemophilum infection in a patient receiving infliximab for psoriasis. Br J Dermatol. 2013;168(2):446-7.

66. Hernández-Torres A, García-Vázquez E, Frías-Iniesta J, Herrero-Martínez JA, Gómez-Gómez J. Cutaneous leishmaniasis in a patient receiving infliximab. Scand J Infect Dis. 2013;45(7):567-9.

67. Safa G, Luce K, Darrieux L, Tisseau L, Ortonne N. Erythrodermic CD8+ pseudolymphoma during infliximab treatment in a patient with psoriasis: use of cyclosporine as a rescue therapy. J Am Acad Dermatol. 2014;71(4): e149-50.

68. Suga H, Sugaya M, Toyama T, Sumida H, Fujita H, Kogure A, et al. A case of mycosis fungoides with large cell transformation associated with infliximab treatment. Acta Derm Venereol. 2014;94(2):233-4.

69. Cavicchini S, Nazzaro G, Marchetti S. Fast-growing 'giant' clear cell acanthoma detected by dermoscopy during treatment with infliximab in a psoriatic patient. J Eur Acad Dermatol Venereol. 2015;29(8):1642-4.

70. Bulur I, Keseroglu HO, Saracoglu ZN, Gönül M. Symmetrical drug-related intertriginous and flexural exanthema (Baboon syndrome) associated with infliximab. J Dermatol Case Rep. 2015;9(1):12-4.

71. Zheng J, Gao Y, Ding Y. Successful management of infliximab-induced generalized pustular psoriasis without therapy discontinuation in a patient with psoriatic arthritis. Dermatol Ther. 2019;32(6):e13132.

72. Canu D, Seneschal J, Milpied B, Taieb A, Darrigade AS. TNFa inhibitor -induced urticaria: a class effect. Eur J Dermatol. 2019;29(5):543-4.

73. Zheng J, Li Y, Ding Y, Gao Y. Secukinumab treatment of tumor necrosis factor antagonists induced paradoxical psoriasis flares in a patient with plaque psoriasis. Dermatol Ther. 2020;33(6):e14455.

74. Papoutsaki M, Chimenti MS, Costanzo A, Talamonti M, Zangrilli A, Giunta A, et al. Adalimumab for severe psoriasis and psoriatic arthritis: an open-label study in 30 patients previously treated with other biologics. J Am Acad Dermatol. 2007;57(2):269-75.

75. Rigopoulos D, Gregoriou S, Lazaridou E, Belyayeva E, Apalla Z, Makris M, et al. Treatment of nail psoriasis with adalimumab: an open label unblinded study. J Eur Acad Dermatol Venereol. 2010;24(5):530-4.

76. Reich K, Armstrong AW, Foley P, Song M, Wasfi Y, Randazzo B, et al. Efficacy and safety of guselkumab, an anti-interleukin-23 monoclonal antibody, compared with adalimumab for the treatment of patients with moderate to severe psoriasis with randomized withdrawal and retreatment: Results from the phase III, double-blind, placebo- and active comparator -controlled VOYAGE 2 trial. J Am Acad Dermatol. 2017;76(3):418-31. 
77. Elewski BE, Baker CS, Crowley JJ, Poulin Y, Okun MM, Calimlim B, et al. Adalimumab for nail psoriasis: efficacy and safety over 52 weeks from a phase-3, randomized, placebo-controlled trial. J Eur Acad Dermatol Venereol. 2019;33(11):2168-78.

78. Bongiorno MR, Pistone G, Doukaki S, Aricò M. Adalimumab for treatment of moderate to severe psoriasis and psoriatic arthritis. Dermatol Ther. 2008;21 Suppl 2:S15-20.

79. Leonardi C, Sobell JM, Crowley JJ, Mrowietz U, Bao Y, Mulani PM, et al. Efficacy, safety and medication cost implications of adalimumab $40 \mathrm{mg}$ weekly dosing in patients with psoriasis with suboptimal response to $40 \mathrm{mg}$ every other week dosing: results from an open-label study. Br J Dermatol. 2012;167(3):658-67.

80. Burmester GR, Panaccione R, Gordon KB, McIlraith MJ, Lacerda AP. Adalimumab: long-term safety in 23458 patients from global clinical trials in rheumatoid arthritis, juvenile idiopathic arthritis, ankylosing spondylitis, psoriatic arthritis, psoriasis and Crohn's disease. Ann Rheum Dis. 2013;72(4):517-24.

81. Menter A, Thaçi D, Papp KA, Wu JJ, Bereswill M, Teixeira HD, et al. Five-year analysis from the ESPRIT 10-year postmarketing surveillance registry of adalimumab treatment for moderate to severe psoriasis. J Am Acad Dermatol. 2015;73(3):410-9.e6.

82. Lanna C, Zangrilli A, Bavetta M, Campione E, Bianchi L. Efficacy and safety of adalimumab in difficult-to-treat psoriasis. Dermatol Ther. 2020; 33(3):e13374.

83. Dalmau J, Roé E, Corella F, García-Navarro X, Peramiquel L, Alomar A. Acute generalized skin eruption due to adalimumab: report of two cases. J Eur Acad Dermatol Venereol. 2007;21(8):1105-6.

84. Bhutani T, Koo J. Paradoxical worsening of psoriasis when switching from etanercept to adalimumab: a case series. J Dermatolog Treat. 2011;22(2): 75-8.

85. Nowsheen S, Kohorst JJ, El-Azhary RA. Adalimumab-induced erythrodermic reactions. Int J Dermatol. 2019;58(10):e204-e6.

86. Hadas E, Bozek A, Cudak A, Ciuk A, Jarząb J. Examples of adverse effects after biological therapy. Postepy Dermatol Alergol. 2020;37(5):712-8.

87. Gonzalo-Garijo MA, Rodríguez-Nevado I, Pérez-Calderón R, Sánchez -Vega S, Pérez-Rangel I. Severe cutaneous reaction and fever due to adalimumab. Ann Allergy Asthma Immunol. 2010;105(6):490-1.

88. Marcella S, Welsh B, Foley P. Development of sarcoidosis during adalimumab therapy for chronic plaque psoriasis. Australas J Dermatol. 2011;52(3):e8-11.

89. Simpkin S, Oakley A. Multiple eruptive squamous cell carcinoma in a patient with chronic plaque psoriasis on adalimumab. Australas J Dermatol. 2013;54(1):55-8.

90. Sousa M, Freitas JP, Antunes J, Soares-de-Almeida L, Filipe PL. Appearance of de novo dysplastic spitzoid compound naevus in an adalimumab-treated psoriatic patient: case report and review of the possible causal relationship with TNF- $\alpha$ blockers. Australas J Dermatol. 2014;55(2):156-7.

91. Stein JE, Patterson-Fortin J, Bodnar BE. Anti-TNF therapy-induced lupus erythematosus-like syndrome in a patient treated with adalimumab for cutaneous psoriasis. BMJ Case Rep. 2018;2018.

92. Özkur E, Altunay İ K, Leblebici C, Topkarcı Z, Erdem Y. Adalimumab -induced scalp psoriasis with severe alopecia. Dermatol Ther. 2019; 32(5):e13033

93. Rodríguez-Cerdeira C, Neissa-Vasquez J, Carnero-Gregorio M, FiaÑo -Valverde C, Muñoz-Garzón V. Myxoid liposarcoma associated with adalimumab treatment: A case report. Mol Clin Oncol. 2019;10(4):454-6.

94. Mease PJ, Goffe BS, Metz J, VanderStoep A, Finck B, Burge DJ. Etanercept in the treatment of psoriatic arthritis and psoriasis: a randomised trial. Lancet. 2000;356(9227):385-90.

95. Tyring S, Gottlieb A, Papp K, Gordon K, Leonardi C, Wang A, et al. Etanercept and clinical outcomes, fatigue, and depression in psoriasis: double-blind placebo-controlled randomised phase III trial. Lancet. 2006;367(9504):29-35.

96. Siegfried EC, Eichenfield LF, Paller AS, Pariser D, Creamer K, Kricorian G. Intermittent etanercept therapy in pediatric patients with psoriasis. J Am Acad Dermatol. 2010;63(5):769-74.

97. Paller AS, Siegfried EC, Eichenfield LF, Pariser D, Langley RG, Creamer K, et al. Long-term etanercept in pediatric patients with plaque psoriasis. J Am Acad Dermatol. 2010;63(5):762-8.

98. Gottlieb AB, Langley RG, Strober BE, Papp KA, Klekotka P, Creamer K, et al. A randomized, double-blind, placebo-controlled study to evaluate the addition of methotrexate to etanercept in patients with moderate to severe plaque psoriasis. Br J Dermatol. 2012;167(3):649-57.
99. Kimball AB, Rothman KJ, Kricorian G, Pariser D, Yamauchi PS, Menter A et al. OBSERVE-5: observational postmarketing safety surveillance registry of etanercept for the treatment of psoriasis final 5-year results. J Am Acad Dermatol. 2015;72(1):115-22.

100. Bovenschen HJ, Tjioe M, Vermaat H, de Hoop D, Witteman BM, Janssens RW, et al. Induction of eruptive benign melanocytic naevi by immune suppressive agents, including biologicals. Br J Dermatol. 2006;154(5):880-4.

101. Fulchiero GJ Jr, Salvaggio H, Drabick JJ, Staveley-O’Carroll K, Billingsley EM, Marks JG, et al. Eruptive latent metastatic melanomas after initiation of antitumor necrosis factor therapies. J Am Acad Dermatol. 2007; 56(5 Suppl):S65-7.

102. Guarneri C, Polimeni G, Nunnari G. Pityriasis rosea during etanercept therapy. Eur Rev Med Pharmacol Sci. 2009;13(5):383-7.

103. Brewer JD, Hoverson Schott AR, Roenigk RK. Multiple squamous cell carcinomas in the setting of psoriasis treated with etanercept: a report of four cases and review of the literature. Int J Dermatol. 2011;50(12):1555-9.

104. Sehgal R, Stratman EJ, Cutlan JE. Biologic Agent-Associated Cutaneous Adverse Events: A Single Center Experience. Clin Med Res. 2018; 16(1-2):41-6.

105. Lee A, Kasama R, Evangelisto A, Elfenbein B, Falasca G. Henoch -Schönlein purpura after etanercept therapy for psoriasis. J Clin Rheumatol. 2006;12(5):249-51.

106. Ly L, Czarnecki D. The rapid onset of multiple squamous cell carcinomas during etanercept treatment for psoriasis. Br J Dermatol. 2007;157(5): 1076-8.

107. Hoang JK, Burruss J. Localized cutaneous Cryptococcus albidus infection in a 14-year-old boy on etanercept therapy. Pediatr Dermatol. 2007;24(3): 285-8.

108. Comte C, Guilhou JJ, Guillot B, Dereure O. Rapid onset and fatal outcome of two squamous cell carcinomas of the genitalia in a patient treated with etanercept for cutaneous psoriasis. Dermatology. 2008;217(3):284-5.

109. Gonzalo-Garijo MA, Pérez-Calderón R, de Argila Fernández-Durán D. Severe generalized exanthema due to etanercept given for severe plaque psoriasis. Ann Allergy Asthma Immunol. 2008;100(6):621-2.

110. Chong BF, Wong HK. Treatment of psoriasis with etanercept in a patient with a history of primary B-cell lymphoma. Clin Exp Dermatol. 2009;34(5):e11-3.

111. Wu J, Vender R, Jambrosic J. Drug-induced lichenoid dermatitis with histopathologic features of mycosis fungoides in a patient with psoriasis. J Cutan Med Surg. 2010;14(6):307-9.

112. Guarneri C, Polimeni G. Nicolau syndrome following etanercept administration. Am J Clin Dermatol. 2010;11 Suppl 1:51-2.

113. Osório F, Magina S, Azevedo F. Primary cutaneous aspergillosis complicating tumor necrosis factor- $\alpha$ blockade therapy in a patient with psoriasis. Actas Dermosifiliogr. 2012;103(10):939-41.

114. Laquer V, Ta T, Nguyen T, Tan B. Mycobacterium poriferae infection in a psoriasis patient on anti-TNF- $\alpha$ therapy. Dermatol Online J. 2013; 19(9):19609.

115. Kavala M, Zindancı I, Türkoglu Z, Can B, Kocatürk E, Senol S, et al. Acute generalized exanthematous pustulosis induced by etanercept: another dermatologic adverse effect. Case Rep Dermatol Med. 2013;2013:601412.

116. Bagel J, Blauvelt A, Nia J, Hashim P, Patekar M, de Vera A, et al. Secukinumab maintains superiority over ustekinumab in clearing skin and improving quality of life in patients with moderate to severe plaque psoriasis: 52-week results from a double-blind phase $3 \mathrm{~b}$ trial (CLARITY). J Eur Acad Dermatol Venereol. 2021;35(1):135-42.

117. Reich K, Papp KA, Blauvelt A, Langley RG, Armstrong A, Warren RB, et al. Bimekizumab versus ustekinumab for the treatment of moderate to severe plaque psoriasis (BE VIVID): efficacy and safety from a 52-week, multicentre, double-blind, active comparator and placebo controlled phase 3 trial. Lancet. 2021;397(10273):487-98.

118. Papp KA, Griffiths CE, Gordon K, Lebwohl M, Szapary PO, Wasfi Y, et al. Long-term safety of ustekinumab in patients with moderate-to -severe psoriasis: final results from 5 years of follow-up. Br J Dermatol. 2013;168(4):844-54.

119. Lipsker D, Lutz V. Cutaneous infarction under IL-12/23 p40 inhibition: a cautionary note. Arch Dermatol. 2011;147(11):1344-5.

120. Young L, Czarnecki D. The rapid onset of multiple squamous cell carcinomas in two patients commenced on ustekinumab as treatment of psoriasis. Australas J Dermatol. 2012;53(1):57-60.

121. Chou WT, Tsai TF. Recurrent erythema annulare centrifugum during ustekinumab treatment in a psoriatic patient. Acta Derm Venereol. 2013; 93(2):208-9. 
122. Morais MR, Meneghello LP, de Oliveira CF, Carvalho AV. Late reaction to ustekinumab infusion. Dermatol Reports. 2013;5(1):e2.

123. Miyachi H, Nakamura Y, Wakabayashi S, Iwasawa MT, Oikawa A, Watanabe A, et al. Case of recurrent severe cellulitis and cutaneous candidiasis during psoriasis treatment with ustekinumab. J Dermatol. 2017;44(8):e206-e7.

124. Ruiz-Villaverde R, Díaz-Martinez MA, Sánchez-Cano D. Multiple Clustered Dermatofibromas Following Ustekinumab Treatment for Psoriasis Vulgaris. Sultan Qaboos Univ Med J. 2017;17(3):e375-e7.

125. Jenkinson H, Thelin L, McAndrew R, Jones KM, Talbott LB, Diven D. Cutaneous protothecosis in a patient on ustekinumab for psoriasis. Int J Dermatol. 2018;57(10):1246-8.

126. Rozenblat M, Cohen-Barak E, Dodiuk-Gad R, Ziv M. Wells' Syndrome Induced by Ustekinumab. Isr Med Assoc J. 2019;21(1):65.

127. King $\mathrm{AD}$, Lam L, Goh C. Onset of frontal fibrosing alopecia during inhibition of Th1/17 Pathways with ustekinumab. Dermatol Online J. 2019;25(7).

128. Lacour JP, Paul C, Jazayeri S, Papanastasiou P, Xu C, Nyirady J, et al. Secukinumab administration by autoinjector maintains reduction of plaque psoriasis severity over 52 weeks: results of the randomized controlled JUNCTURE trial. J Eur Acad Dermatol Venereol. 2017;31(5): 847-56.

129. Bissonnette R, Luger T, Thaçi D, Toth D, Messina I, You R, et al. Secukinumab sustains good efficacy and favourable safety in moderate -to-severe psoriasis after up to 3 years of treatment: results from a double-blind extension study. Br J Dermatol. 2017;177(4):1033-42.

130. Costanzo A, Bianchi L, Flori ML, Malara G, Stingeni L, Bartezaghi M, et al. Secukinumab shows high efficacy irrespective of HLA-Cw6 status in patients with moderate-to-severe plaque-type psoriasis: SUPREME study. Br J Dermatol. 2018;179(5):1072-80.

131. Thaçi D, Puig L, Reich K, Tsai TF, Tyring S, Kingo K, et al. Secukinumab demonstrates sustained efficacy in clearing skin and improving patient -reported outcomes in patients with moderate-to-severe psoriasis through 2 years of treatment: Results from the CLEAR study. J Am Acad Dermatol. 2019;81(6):1405-9.

132. Reich K, Sullivan J, Arenberger P, Jazayeri S, Mrowietz U, Augustin M, et al. Secukinumab shows high and sustained efficacy in nail psoriasis: 2.5-year results from the randomized placebo-controlled TRANSFIGURE study. Br J Dermatol. 2021;184(3):425-36.

133. Reich K, Körber A, Mrowietz U, Sticherling M, Sieder C, Früh J, et al. Secukinumab 2-weekly vs. 4-weekly dosing in patients with plaque-type psoriasis: results from the randomized GAIN study. Br J Dermatol. 2021;184(5):849-56.

134. Reich K, Warren RB, Lebwohl M, Gooderham M, Strober B, Langley RG, et al. Bimekizumab versus Secukinumab in Plaque Psoriasis. N Engl J Med. 2021; Apr 23. doi: 10.1056/NEJMoa2102383. [Epub ahead of print]

135. Galluzzo M, Talamonti M, De Simone C, D’Adamio S, Moretta G, Tambone S, et al. Secukinumab in moderate-to-severe plaque psoriasis: a multi-center, retrospective, real-life study up to 52 weeks observation. Expert Opin Biol Ther. 2018;18(7):727-35.

136. Yoo J, Shah F, Velangi S, Stewart G, Scarisbrick JS. Secukinumab for treatment of psoriasis: does secukinumab precipitate or promote the presentation of cutaneous T-cell lymphoma? Clin Exp Dermatol. 2019; 44(4):414-7.

137. Peigottu MF, Montesu MA. Adverse skin reaction to Secukinumab. J Eur Acad Dermatol Venereol. 2017;31(10):e432-e3.

138. Wehrmann C, Sondermann W, Körber A. [Secukinumab-induced subacute-cutaneous lupus erythematosus]. Hautarzt. 2018;69(1):64-6.

139. Dogra S, Bishnoi A, Narang T, Handa S. Secukinumab-induced paradoxical pustular psoriasis. Clin Exp Dermatol. 2019;44(1):72-3.

140. Burlando M, Cozzani E, Russo R, Parodi A. Atopic-like dermatitis after secukinumab injection: A case report. Dermatol Ther. 2019;32(1):e12751.

141. Blackcloud P, Dupuy E, Kang Y, Smart C, Hsiao J. Bullous acral eruption related to secukinumab. Dermatol Online J. 2019;25(6).

142. Fox JD, Aramin H, Ghiam N, Freedman JB, Romanelli P. Secukinumab -associated localized granuloma annulare (SAGA): a case report and review of the literature. Dermatol Online J. 2020;26(8).

143. Eichhoff G. Secukinumab-induced pompholyx in a psoriasis patient. Dermatol Online J. 2020;26(4).

144. Fisher S, Ziv M. Skin and soft tissue infections in biological therapy for psoriasis-A case report and systematic review of the literature. Int J Dermatol. 2021; Jun 3. doi: 10.1111/ijd.15679. [Epub ahead of print]
145. Saeki H, Nakagawa H, Nakajo K, Ishii T, Morisaki Y, Aoki T, et al. Efficacy and safety of ixekizumab treatment for Japanese patients with moderate to severe plaque psoriasis, erythrodermic psoriasis and generalized pustular psoriasis: Results from a 52-week, open-label, phase 3 study (UNCOVER-J). J Dermatol. 2017;44(4):355-62.

146.Langley RG, Papp K, Gooderham M, Zhang L, Mallinckrodt C, Agada $\mathrm{N}$, et al. Efficacy and safety of continuous every-2-week dosing of ixekizumab over 52 weeks in patients with moderate-to-severe plaque psoriasis in a randomized phase III trial (IXORA-P). Br J Dermatol. 2018; 178(6):1315-23.

147. Leonardi C, Maari C, Philipp S, Goldblum O, Zhang L, Burkhardt N, et al. Maintenance of skin clearance with ixekizumab treatment of psoriasis: Three-year results from the UNCOVER-3 study. J Am Acad Dermatol. 2018;79(5):824-30.e2

148. Paller AS, Seyger MMB, Alejandro Magariños G, Bagel J, Pinter A, Cather J, et al. Efficacy and safety of ixekizumab in a phase III, randomized, double-blind, placebo-controlled study in paediatric patients with moderate-to-severe plaque psoriasis (IXORA-PEDS). Br J Dermatol. 2020;183(2):231-41.

149. Blauvelt A, Leonardi C, Elewski B, Crowley JJ, Guenther LC, Gooderham $\mathrm{M}$, et al. A head-to-head comparison of ixekizumab vs. guselkumab in patients with moderate-to-severe plaque psoriasis: 24-week efficacy and safety results from a randomized, double-blinded trial. Br J Dermatol. 2021;184(6):1047-58.

150. Anthony E, Rajgopal Bala H, Goh MS, Balta S, Foley P. Ixekizumab -treatment-emergent photosensitive cutaneous eruption. Australas J Dermatol. 2018;59(4):e284-e6.

151. Oiwa T, Fujita M, Takase S, Nishimura Y, Ota M, Okada K, et al. A Case of Ixekizumab-induced Psoriasiform Eruption. Acta Derm Venereol. 2019; 99(4):446-7.

152. Seo SJ, Shin BS, Lee JH, Jeong H. Efficacy and safety of brodalumab in the Korean population for the treatment of moderate to severe plaque psoriasis: A randomized, phase III, double-blind, placebo-controlled study. J Dermatol. 2021;48(6):807-17.

153. Pinter A, Hoffmann M, Reich K, Augustin M, Kaplan K, Gudjónsdóttir SD, et al. A phase 4, randomized, head-to-head trial comparing the efficacy of subcutaneous injections of brodalumab to oral administrations of fumaric acid esters in adults with moderate-to-severe plaque psoriasis (CHANGE). J Eur Acad Dermatol Venereol. 2021;35(3):701-11.

154. Takahashi H, Sato K, Takagi A, Iizuka H. Brodalumab-induced palmar pustular eruption and joint swelling accompanied by muscle pains in two cases of psoriasis. J Dermatol. 2018;45(11):e325-e6.

155. Kobayashi M, Nagata M, Oaku S, Kanda N, Tada Y, Aozasa N. Two cases of skin infection during psoriasis treatment with brodalumab. J Dermatol. 2018;45(3):e51-e2.

156. Glatt S, Helmer E, Haier B, Strimenopoulou F, Price G, Vajjah P, et al. First-in-human randomized study of bimekizumab, a humanized monoclonal antibody and selective dual inhibitor of IL-17A and IL-17F, in mild psoriasis. Br J Clin Pharmacol. 2017;83(5):991-1001.

157. Blauvelt A, Papp KA, Merola JF, Gottlieb AB, Cross N, Madden C, et al. Bimekizumab for patients with moderate to severe plaque psoriasis: 60-week results from BE ABLE 2, a randomized, double-blinded, placebo-controlled, phase $2 \mathrm{~b}$ extension study. J Am Acad Dermatol. 2020;83(5):1367-74.

158. Nemoto O, Hirose K, Shibata S, Li K, Kubo H. Safety and efficacy of guselkumab in Japanese patients with moderate-to-severe plaque psoriasis: a randomized, placebo-controlled, ascending-dose study. Br J Dermatol. 2018;178(3):689-96.

159. Thaçi D, Pinter A, Sebastian M, Termeer C, Sticherling M, Gerdes S, et al. Guselkumab is superior to fumaric acid esters in patients with moderate-to-severe plaque psoriasis who are naive to systemic treatment: results from a randomized, active-comparator-controlled phase IIIb trial (POLARIS). Br J Dermatol. 2020;183(2):265-75.

160. Maliyar K, O’Toole A, Gooderham MJ. Long-Term Single Center Experience in Treating Plaque Psoriasis With Guselkumab. J Cutan Med Surg. 2020;24(6):588-95.

161. Kopp T, Riedl E, Bangert C, Bowman EP, Greisenegger E, Horowitz A, et al. Clinical improvement in psoriasis with specific targeting of interleukin-23. Nature. 2015;521(7551):222-6.

162. Papp K, Thaçi D, Reich K, Riedl E, Langley RG, Krueger JG, et al. Tildrakizumab (MK-3222), an anti-interleukin-23p19 monoclonal antibody, improves psoriasis in a phase IIb randomized placebo -controlled trial. Br J Dermatol. 2015;173(4):930-9. 


\section{APJAI}

163. Imafuku S, Nakagawa H, Igarashi A, Morita A, Okubo Y, Sano S, et al. Long-term efficacy and safety of tildrakizumab in Japanese patients with moderate to severe plaque psoriasis: Results from a 5-year extension of a phase 3 study (reSURFACE 1). J Dermatol. 2021;48(6):844-52.

164. Krueger JG, Ferris LK, Menter A, Wagner F, White A, Visvanathan S, et al. Anti-IL-23A mAb BI 655066 for treatment of moderate-to-severe psoriasis: Safety, efficacy, pharmacokinetics, and biomarker results of a single-rising-dose, randomized, double-blind, placebo-controlled trial. J Allergy Clin Immunol. 2015;136(1):116-24.e7.
165. Gordon KB, Strober B, Lebwohl M, Augustin M, Blauvelt A, Poulin Y, et al. Efficacy and safety of risankizumab in moderate-to-severe plaque psoriasis (UltIMMa-1 and UltIMMa-2): results from two double-blind, randomised, placebo-controlled and ustekinumab-controlled phase 3 trials. Lancet. 2018;392(10148):650-61.

166. Papp KA, de Vente S, Zeng J, Flack M, Padilla B, Tyring SK. Long-Term Safety and Efficacy of Risankizumab in Patients with Moderate-to-Severe Chronic Plaque Psoriasis: Results from a Phase 2 Open-Label Extension Trial. Dermatol Ther (Heidelb). 2021;11(2):487-97. 